Article

\title{
Skeletal Muscle Response to Deflazacort, Dexamethasone and Methylprednisolone
}

\author{
Alan Fappi ${ }^{\circledR}$, Juliana de Carvalho Neves ${ }^{\circledR}$, Leandro Nunes Sanches, \\ Pedro Victor Massaroto e Silva ${ }^{\circledR}$, Guilherme Yuiti Sikusawa ${ }^{\circledR}$,

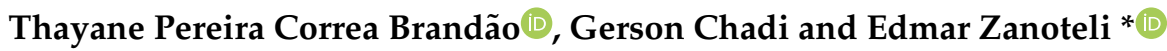 \\ Department of Neurology, Faculdade de Medicina FMUSP, Universidade de Sao Paulo, São Paulo, SP 01246-904, \\ Brazil; alanfappi@usp.br (A.F.); jcneves@usp.br (J.d.C.N.); leandronsan@usp.br (L.N.S.); \\ ppvmassa@hotmail.com (P.V.M.eS.); guilhermeys@uol.com.br (G.Y.S.); thayane.cpb@outlook.com (T.P.C.B.); \\ gerchadi@usp.br (G.C.) \\ * Correspondence: edmar.zanoteli@usp.br
}

Received: 7 March 2019; Accepted: 23 April 2019; Published: 1 May 2019

\begin{abstract}
Glucocorticoids represent some of the most prescribed drugs that are widely used in the treatment of neuromuscular diseases, but their usage leads to side effects such as muscle atrophy. However, different synthetic glucocorticoids can lead to different muscle effects, depending upon its chemical formulation. Here, we intended to demonstrate the muscle histologic and molecular effects of administering different glucocorticoids in equivalency and different dosages. Methods: Seventy male Wistar rats distributed into seven groups received different glucocorticoids in equivalency for ten days or saline solution. The study groups were: Control group (CT) saline solution; dexamethasone (DX) 1.25 or $2.5 \mathrm{mg} / \mathrm{kg} /$ day; methylprednisolone (MP) 6.7 or $13.3 \mathrm{mg} / \mathrm{kg} /$ day; and deflazacort (DC) 10 or $20 \mathrm{mg} / \mathrm{kg} /$ day. At the end of the study, the animals were euthanized, and the tibialis anterior and gastrocnemius muscles were collected for metachromatic ATPase (Cross-sectional area (CSA) measurement), Western blotting (protein expression of IGF-1 and Ras/Raf/MEK/ERK pathways) and RT-PCR (MYOSTATIN, MuRF-1, Atrogin-1, REDD-1, REDD-2, MYOD, MYOG and IRS1/2 genes expression) experiments. Results: Muscle atrophy occurred preferentially in type 2B fibers in all glucocorticoid treated groups. DC on $10 \mathrm{mg} / \mathrm{kg} /$ day was less harmful to type $2 \mathrm{~B}$ fibers CSA than other doses and types of synthetic glucocorticoids. In type 1 fibers CSA, lower doses of DC and DX were more harmful than high doses. DX had a greater effect on the IGF-1 pathway than other glucocorticoids. MP more significantly affected P-ERK1/2 expression, muscle fiber switching (fast-to-slow), and expression of REDD1 and MyoD genes than other glucocorticoids. Compared to DX and MP, DC had less of an effect on the expression of atrogenes (MURF-1 and Atrogin-1) despite increased MYOSTATIN and decreased IRS-2 genes expression. Conclusions: Different glucocorticoids appears to cause muscle atrophy affecting secondarily different signaling mechanisms. MP is more likely to affect body/muscles mass, MEK/ERK pathway and fiber type transition, DX the IGF-1 pathway and IRS1/2 expression. DC had the smallest effect on muscle atrophic response possibly due a delayed timing on atrogenes response.
\end{abstract}

Keywords: glucocorticoid; skeletal muscle; muscle atrophy; IGF-1; MEK/ERK; Myostatin

\section{Introduction}

The glucocorticoids (cortisol or hydrocortisone) are cholesterol-derived hormones that are produced in the zona fasciculata of the adrenal glands cortex [1]. Moreover, many studies have indicated an extra-adrenal cortisol production, for example, in the primary lymphoid organs, intestines, cardiovascular system, and central nervous system [2-4]. Glucocorticoid hormones serve to influence 
several functions, which include glycemic control, glycogen metabolism, anti-inflammatory response and immunosuppressive therapy.

Glucocorticoid treatment comprises several conditions including endocrine and non-endocrine scenarios, as well as hormonal replacement in adrenal insufficiency besides inflammatory/auto-immune and lymphoproliferative disorders [5,6]. Glucocorticoids such as Deflazacort ${ }^{\mathrm{TM}}$ are widely used as first-line treatments in Duchenne's muscular dystrophy (DMD), bringing a better disease-course prognosis regarding motor skills, muscle strength, respiratory conditions, and cardiac function [7-9].

Although indicated in certain cases, glucocorticoids' long-term use, dosage, administration route, and type lead to negative effects comprising several changes in the whole-body physiology that affects several organ systems, such as the gastrointestinal, dermatological, neurological, endocrinological, ophthalmologic, cardiovascular, and musculoskeletal systems. Regarding the musculoskeletal system, the main side effects include muscle myopathy/atrophy, osteoporosis/osteopenia, bone necrosis, pathological fracture of the long bones, tendon rupture, and muscle insulin-resistance $[10,11]$. It is important to point out that the glucocorticoid-induced muscle atrophy is one of the most common drug-induced myopathies, with an approximate incidence of $60 \%$ [12].

During the muscle atrophy process by glucocorticoids, there is an increased muscle degradation associated with an inhibition of muscle synthesis, leading to an atrophic state of the tissue [11]. The impact upon Akt phosphorylation leads to repression of the mTORC1 (mTOR complex, composed of mTOR, Raptor, MLST8, PRAS40 and DEPTOR) suppressing downstream proteins such as P70S6K and elf4E (related to the initiation phase of mRNA translation), and consequently reducing protein synthesis [13-15]. The degradation process occurs by an increased transcription of REDD1 and REDD2, high activation of the Myostatin/Smad2/3 pathway [11] and-though incompletely understood-activation of the Ras/Raf/MEK/ERK pathway.

Glucocorticoid effects occur preferentially on the fast-twitch skeletal muscle, with few or no effect on the slow twitch muscle and cardiac muscle, in part explained by the PGC- $1 \alpha$ expression [16] and differential glucocorticoid receptor (GR) expression between fiber types [17].

The atrophic state produced by glucocorticoids is resultant of autophagy-lysosome and mainly by the ubiquitin proteasome system activation [18] with a highly regulated expression of Atrophy F-box (MAFbx/Atrogin-1) and Muscle Specific Ring Finger Protein 1 (MuRF1). Atrogin-1 and MuRF-1 are E-3 ligases transcript by FOXO1/3a [18] and KLF15 [17] and are considered necessary requisites for the muscle atrophy by glucocorticoids $[19,20]$.

Many studies have compared different glucocorticoids in a wide variety of conditions in order to better describe their responses to a given condition, which makes certain medicines more eligible in the clinical approach. Trials comparing the side effects of glucocorticoids administration are common for the DMD treatment. Since the 1980's, after the establishment of the Clinical Investigation group of Duchenne Dystrophy (CIDD), many studies have been shown that Deflazacort leads to fewer side effects during chronic medication in comparison to prednisone (first promising test by CIDD) considering bone mineralization [21,22], and glucose tolerance [23], but with comparable effects considering the efficacy to the progression of DMD with the advantage of fewer side effects [24] despite being more likely associated to the development of cataracts $[25,26]$. However, some of the studies point to differences in lean body mass between people treated with different groups of glucocorticoids, even though the dystrophic pattern makes the evaluation of muscle mass gain/loss difficult; this leads to the conduct of comparative studies of the effect of glucocorticoid in a healthy system, which are scarce and few employ glucocorticoid drugs in healthy species by exploring the equivalency and cell changes, possible interventions while attenuating their side effects. The few available studies have shown opposite effects in the diaphragm and gastrocnemius muscles. Dekhuijzen et al. (1995) [27] showed that in rats, Deflazacort, more so than methylprednisolone (equivalent doses), was harmful to the areas of peripheral muscles as well as the diaphragm. Anderson et al. (1996) have found that Deflazacort but not prednisone improves both muscle repair and fiber growth in the diaphragm [28]. 
Considering the lack of comparative analysis of glucocorticoid-induced muscle atrophy in healthy individuals, this work aimed to evaluate the impact of three main classes of glucocorticoid drugs (dexamethasone, methylprednisolone, and deflazacort) in two doses, in terms of pharmaceutical equivalency, on healthy Wistar rats with respect to the muscle fiber size, proportion, and cell trophism signaling.

\section{Material and Methods}

\subsection{Animals and Drug Treatment}

Male Wistar rats (70 animals) between 10 and 12 weeks of age and weighing between 320 to $350 \mathrm{~g}$ were used. The animals were housed in cages containing no more than three individuals under dark-light cycles for $12 \mathrm{~h}$ each at $25^{\circ} \mathrm{C}$ and received food and water ad libitum. The animals were provided with commercial feed (Nuvital, Nuvilab CR-1, NUVITAL Nutrientes LTDA, Curitiba, Brazil) containing crude protein $(\min 22.0 \%)$, ethereal extract $(\min 4.5 \%)$, mineral matter $(\max 1 \mathrm{~d} 0.0 \%)$, fibrous matter $(\max 8.0 \%)$, calcium $(\max 1.4 \%)$, phosphor (min $0.8 \%)$, vitamin $\mathrm{A}(25,200.00 \mathrm{UI} / \mathrm{kg})$, vitamin D3 (2100.00 UI/kg), vitamin E $(60.00 \mathrm{mg} / \mathrm{kg})$, vitamin K3 $(12.50 \mathrm{mg} / \mathrm{kg})$, vitamin B1 $(14.40 \mathrm{mg} / \mathrm{kg})$, vitamin B2 $(11.00 \mathrm{mg} / \mathrm{kg})$, vitamin B6 $(12.00 \mathrm{mg} / \mathrm{kg})$, vitamin B12 $(60.00 \mathrm{mcg} / \mathrm{kg})$, niacin $(60.00 \mathrm{mg} / \mathrm{kg})$, pantothenic acid $(112.00 \mathrm{mg} / \mathrm{kg})$, folic acid $(6.00 \mathrm{mg} / \mathrm{kg})$, biotin $(0.26 \mathrm{mg} / \mathrm{kg})$, choline $(1100.00 \mathrm{mg} / \mathrm{kg})$, iron $(50.00 \mathrm{mg} / \mathrm{kg})$, zinc $(60.00 \mathrm{mg} / \mathrm{kg})$, copper $(10.00 \mathrm{mg} / \mathrm{kg})$, iodine $(2.00 \mathrm{mg} / \mathrm{kg})$, manganese $(60.00 \mathrm{mg} / \mathrm{kg})$, selenium $(0.05 \mathrm{mg} / \mathrm{kg})$, cobalt $(1.50 \mathrm{mg} / \mathrm{kg})$, lysine $(100.00 \mathrm{mg} / \mathrm{kg})$, methionine $(300.00 \mathrm{mg} / \mathrm{kg})$, and antioxidant $(100.00 \mathrm{mg} / \mathrm{kg})$. All in vivo experiments were approved by our local research ethics committee (CEUA FMUSP, process 430/2013) and were performed according to the NIH guidelines on the care, handling, and use of laboratory animals.

\subsection{Glucocorticoid Administration}

Dexamethasone doses were established according to previously used and well defined doses able to induce significant muscle atrophy in this model $[29,30]$ and the other glucocorticoids classes were adjusted to its dose equivalency according to the available literature [31,32].

Initially, all 70 animals were kept in their cages for a 30-day period with periodic body weight checks. After this period, the animals received one of the following glucocorticoid doses administered via the designated pathway: Dexamethasone (injectable Decadron ${ }^{\circledR} 4 \mathrm{mg} / \mathrm{mL}$, Áche laboratories, São Paulo, Brazil) subcutaneously (s.c.) injected in the dorsal region at doses of $2.5 \mathrm{mg} / \mathrm{kg} / \mathrm{day}$ or $1.25 \mathrm{mg} / \mathrm{kg} / \mathrm{day}$ for 10 days; Methylprednisolone (methylprednisolone acetate, injectable suspension, Depo-Medrol ${ }^{\circledR}$ $40 \mathrm{mg} / \mathrm{mL}$, Pfizer, New York, NY, USA) via intramuscular (i.m.) injection into the hamstring region at doses of $13.3 \mathrm{mg} / \mathrm{kg} /$ day or $6.7 \mathrm{mg} / \mathrm{kg} /$ day for 10 days; and Deflazacort (manufactured oral suspension, $40 \mathrm{mg} / \mathrm{mL}$, Rhamus Laboratory, São Paulo, Brazil) via gavage (v.g.) at doses of $20 \mathrm{mg} / \mathrm{kg} / \mathrm{day}$ or $10 \mathrm{mg} / \mathrm{kg} /$ day for 10 days. The control group $(\mathrm{CT})$ received only saline solution $(0.9 \% \mathrm{NaCl}$ in ultrapure water) delivered via intramuscular injection into the hamstrings for 10 days. The injections were applied at approximately 1 p.m. alternating sides and locality to prevent wounds and avoid animal stress.

At the end of the experiment, seven study groups were established: (1) the CT group (i.m. saline solution administration for 10 days), (2) the DX1.25 group (s.c. $1.25 \mathrm{mg} / \mathrm{kg} /$ day of dexamethasone administration for 10 days), (3) the DX2.5 group (s.c. $2.5 \mathrm{mg} / \mathrm{kg} /$ day of dexamethasone administration for 10 days), (4) the MP13 group (i.m. $13.3 \mathrm{mg} / \mathrm{kg} /$ day of methylprednisolone administration for 10 days), (5) the MP6 group (i.m. $6.7 \mathrm{mg} / \mathrm{kg} /$ day of methylprednisolone administration for 10 days), (6) the DC20 group (10 days of v.g. $20 \mathrm{mg} / \mathrm{kg} /$ day of deflazacort administration), and (7) the DC10 group (v.g. $10 \mathrm{mg} / \mathrm{kg} /$ day of deflazacort administration for 10 days).

After 10 days of glucocorticoids treatment, the animals were euthanized with an intraperitoneal injection of sodium pentobarbital $(30 \mathrm{mg} / \mathrm{kg})$ and their gastrocnemius (GA) and tibialis anterior (TA) muscles and adrenal glands (AGs) were immediately dissected, weighed, snap frozen in isopentane cooled in liquid nitrogen (muscles collected for histology), and stored at $-80^{\circ} \mathrm{C}$. 


\subsection{Cross-Sectional Areas Evaluation}

TA cross-sections were performed in cryostat (Leica, model CM3000, Leica Biosystems, Wetzlar, Germany) at $-25^{\circ} \mathrm{C}$. The sections were submitted to the metachromatic dye-ATPase method (mATPase) according to Ogilvie and Feeback [33] to differentiate the main muscle fiber subtypes (e.g., 1, 2A, and 2B). Slides were photographed at 20X (Olympus, microscope AX70, camera and software Olympus DP72), and the cross-sectional areas (CSA) were measured for each muscle fiber subtype using the analysis tool in the Photoshop CS6 extended software. Prior to the measurements, a pixel-to-micrometer conversion scale was established in the Image J software (java 8 for Windows, NIH, Bethesda, MD, USA) based on pictures of a micrometer slide at the same magnification (20X). An average of 350 fibers of each muscle fragment (animal) was measured.

\subsection{SDS-PAGE (Western Blotting)}

TA fragments were homogenized with cooled RIPA buffer (PBS pH 7.4, 0.5\% sodium deoxycholate, 0.1\% SDS, 1 mM EDTA pH 8.0, 1 mM EGTA pH 8.0, 50 mM Tris-Hcl, 1\% NP-40, $10 \mathrm{mM} \mathrm{NaOV,} 10 \mathrm{mM}$ NaPyr, $50 \mathrm{mM} \mathrm{NaF}$, and 1\% protease inhibitor Sigma P8340) in 20X w/v and centrifuged for $5 \mathrm{~min}$ at $4{ }^{\circ} \mathrm{C}$ at $16,100 \mathrm{~g}$. The supernatants were quantified using Bradford reagent (Bio-Rad, $\# 500-0006$, Hercules, CA, USA) and the BSA standard curve. The samples were boiled at $100^{\circ} \mathrm{C}$ for $5 \mathrm{~min}$ and then applied to 8 or $10 \%$ bis-acrylamide mini-gels, within 50 to $80 \mu \mathrm{g}$ protein load per well. In sequence, the samples were transferred to PVDF or nitrocellulose membranes at $65 \mathrm{~V}$ for $1 \mathrm{~h}$ in a Criterion Blotter (Bio-Rad) apparatus. The membranes were blocked in 5\% BSA for $1 \mathrm{~h}$ and incubated overnight with primary antibody (1:1000) diluted in a blocking solution. Anti-rabbit HRP-conjugated secondary antibody (GE Healthcare Bio-Sciences, \#NA934, Pittsburgh, PA, USA) [1:10,000] diluted in a blocking solution (5\% BSA in TBS-T) was incubated for $1 \mathrm{~h}$ at room temperature and then the ECL (Enhanced Chemiluminescent) reagent (Millipore/Sigma, \#WBKLS0500, Burlington, MA, USA) was incubated for $5 \mathrm{~min}$, prior to scanning in the C-DiGit Blot Scanner (LI-COR Biosciences, Lincoln, NE, USA) for $12 \mathrm{~min}$. For protein loading control, labeling densities were normalized by membrane staining against total protein across the lane $(250-10 \mathrm{kDa})$ of the correspondent sample. Line blots of approximate weight "total protein" are displayed in each corresponding graph for illustration. Blots were analyzed with the Image Studio software version 4.0 (LI-COR).

The primary antibodies used included anti-Akt pan (Cell Signaling Technology, \#4691, Danvers, MA, USA), anti-P-Akt (Ser473) (Cell Signaling, \#4060), anti-GSK-3ß (Cell Signaling, \#9315), anti-P-GSK-3 $\beta$ (Ser9) (Cell Signaling, \#9322), anti-FOXO3a (Cell Signaling, \#2497), anti-P-FOXO3a (Ser253) (Cell Signaling, \#9466), anti-ERK1/2 (Cell Signaling, \#4695), and anti-P-ERK1/2 (Thr202/Tyr204) (Cell Signaling, \#4377).

\subsection{Quantitative PCR}

The total RNA was extracted from $30 \mathrm{mg}$ of GA muscles using the SV Total RNA Isolation System (Promega, \#Z3105, Madison, WI, USA) according to the guidelines for the preparation of lysates from small tissue samples. RNA pellets were resuspended in $50 \mu \mathrm{L}$ nuclease-free water for a final RNA concentration of $500 \mathrm{ng} / \mu \mathrm{L}$. RNA purity and integrity were tested by the spectrophotometry and agarose gel, respectively. In sequence, reverse transcription reactions were performed using the GoScript Reverse Transcription Mix Kit (Promega, \#A2801) following the manufacturer's instructions. Quantitative PCR was done in duplicate with a GoTaq qPCR Master Mix (Promega, \#A6002) loading [75 ng] of cDNA and $50 \mathrm{nM}$ of sense and antisense primers in a Piko Real 96 (Thermo Scientific, TCR0096, Waltham, MA, USA) equipment. The data obtained were systematized and analyzed according to the calculation of $2^{-\triangle \Delta C T}$.

Primer sequences: MURF-1 forward TCGACATCTACAAGCAGGAA, reverse CTGTCCTTGG AAGATGCTTT; Atrogin-1/MAFbx forward TGAAGACCGGCTACTGTGGAAGAGAC, reverse TTGGGGTGAAAGTGAGACGGAGCAG; REDD-1 forward CACCGGCTTCAGAGTCATCA, 
reverse CGGGTCTCCACCACAGAAAT; REDD-2 forward CTTCAGCGTCTGGTGAAATCC, reverse ATGCTGGCCGTGTTCTTACTG; IRS-1 forward CCCGGTCGGTGCCAAATAGC, reverse GCCACTGGTGAGGTATCCACATAGC; IRS-2 forward CCACACACCTGTCCTCATTG, reverse TAATCCGCTTTGCCAAAATC; GAPDH forward ACGCCAGTAGACTCCACGAC, reverse ATGACTCTACCCACGGCAAG.

\subsection{Statistical Analysis}

The quantitative results were analyzed in the GraphPad Prism 5.0 software (GraphPad Software, San Diego, CA, USA). They were initially classified according to normality using the Shapiro-Wilk normality test and then evaluated with the appropriate statistical tests. The differences between means were analyzed using the unpaired Student's t-test, and differences among groups were analyzed by one-way ANOVA followed by the Bonferroni post hoc test. The test used, and the number of individuals per group, are described in the presentation of each result. Variations with $P<0.05$ were considered statistically significant.

\section{Results}

\subsection{Body and Tissue Weights Resulting from Different Glucocorticoids Administration}

There was a linear, progressive and equivalent weight gain of all animals up to the beginning of drug administration (Figure 1). From the second to the 10th day of glucocorticoids' administration, a significant decrease in the body weight of the animals on the glucocorticoid treatment was observed in relation to the control group ( $P<0.001$ for all groups) at the end of the study (Table 1$)$. It was observed that the mean body weight of animals receiving MP at the $13.3 \mathrm{mg} / \mathrm{kg} /$ day dose was significantly lower than the groups receiving DX at $2.5 \mathrm{mg} / \mathrm{kg} / \mathrm{day}$ and DC at $20 \mathrm{mg} / \mathrm{kg} /$ day $(P<0.01$ in both comparisons). Comparing pre- and post-glucocorticoid administration, the DX1.25 group had a body weight loss of $22.4 \%$, the other group results were DX2.5, 24.31\%; DC10, 15.59\%; DC20, 21.56\%; MP6, 27.79\%; and MP13, 32.70\%.

\section{Body mass}

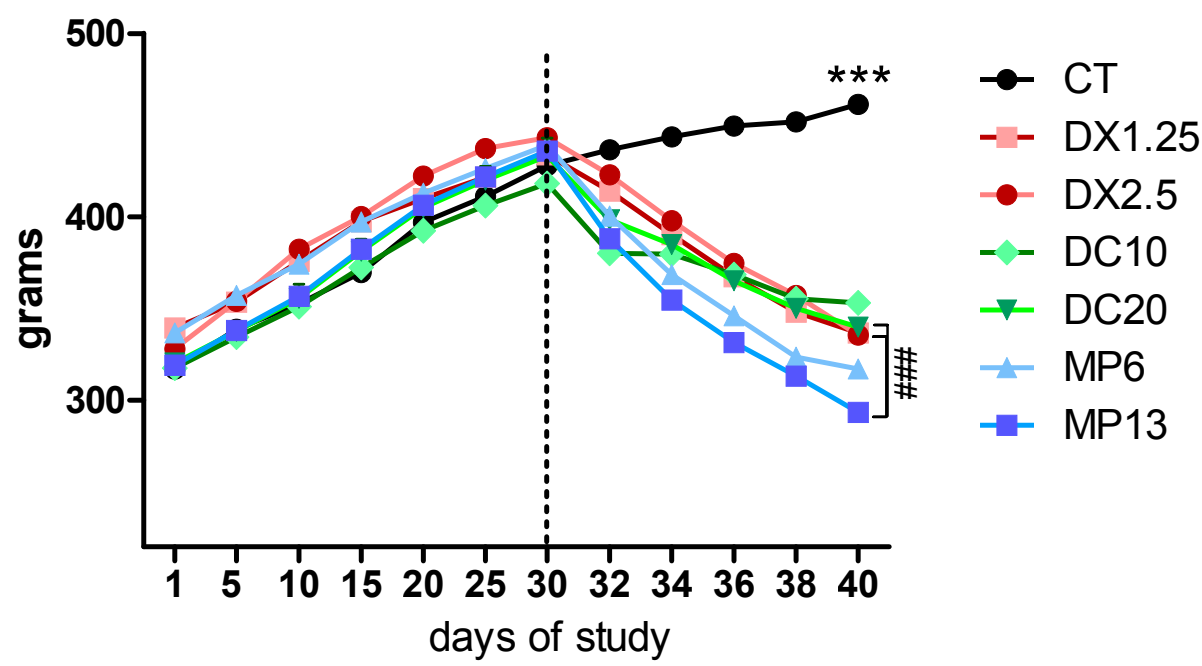

Figure 1. Body mass during the study. The dotted line represents the initial moment of glucocorticoid administration. Asterisks represent statistical difference between the control groups (CT) vs. all groups (\#) represent statistical difference between groups. Data are presented as mean. ${ }^{* * *}$ or \#\#\# $=P<0.001$. 
Table 1. Body mass average during the study.

\begin{tabular}{|c|c|c|c|c|c|c|c|}
\hline \multirow{2}{*}{ Groups } & \multicolumn{7}{|c|}{ Days of Study } \\
\hline & 1 & 30 & 32 & 34 & 36 & 38 & 40 \\
\hline $\mathrm{CT}$ & $317.0 \mathrm{~g}$ & $427.9 \mathrm{~g}$ & $436.5 \mathrm{~g}$ & $443.7 \mathrm{~g}$ & $449.5 \mathrm{~g}$ & $451.8 \mathrm{~g}$ & $461.4 \mathrm{~g}$ \\
\hline DX1.25 & $339.4 \mathrm{~g}$ & $433.9 \mathrm{~g}$ & $414.1 \mathrm{~g}$ & $390.4 \mathrm{~g} * * *$ & $367.4 \mathrm{~g} * * *$ & $348.0 \mathrm{~g} * * *$ & $336.7 \mathrm{~g} * * *$ \\
\hline DX2.5 & $328.1 \mathrm{~g}$ & $443.3 \mathrm{~g}$ & $422.9 \mathrm{~g}$ & $398.0 \mathrm{~g}^{* *}$ & $374.6 \mathrm{~g}^{* * *}$ & $357.1 \mathrm{~g}^{* * *}$ & $335.5 \mathrm{~g} * * *$ \\
\hline DC10 & $317.5 \mathrm{~g}$ & $418.2 \mathrm{~g}$ & $380.2 \mathrm{~g}^{* * *}$ & $379.7 \mathrm{~g}^{* * *}$ & $368.5 \mathrm{~g} * * *$ & $355.3 \mathrm{~g}^{* * *}$ & $353.0 \mathrm{~g} * * *$ \\
\hline DC20 & $320.3 \mathrm{~g}$ & $433.2 \mathrm{~g}$ & $398.4 \mathrm{~g}^{* *}$ & $385.0 \mathrm{~g}^{* * *}$ & $365.2 \mathrm{~g}^{* * *}$ & $350.0 \mathrm{~g}^{* * *}$ & $339.8 \mathrm{~g} * * *$ \\
\hline MP6 & $336.6 \mathrm{~g}$ & $439.0 \mathrm{~g}$ & $400.5 \mathrm{~g} *$ & $368.5 \mathrm{~g} * * *$ & $346.0 \mathrm{~g}^{* * *}$ & $323.4 \mathrm{~g}^{* * *}$ & $317.0 \mathrm{~g} * * *$ \\
\hline MP13 & $319.1 \mathrm{~g}$ & $436.0 \mathrm{~g}$ & $388.1 \mathrm{~g} * * *$ & $\begin{array}{c}354.8 \mathrm{~g} * * * \\
\text { \#\# vs. } \\
\text { DX2.5 }\end{array}$ & $\begin{array}{c}331.4 \mathrm{~g} * * * \\
\text { \#\# vs. } \\
\text { DX2.5 }\end{array}$ & $\begin{array}{c}313.1 \mathrm{~g} * * * \\
\text { \#\# vs. } \\
\text { DX2.5 } \\
\text { \# vs. DC20 }\end{array}$ & $\begin{array}{c}293.4 \mathrm{~g} * * * \\
\text { \#\# vs. } \\
\text { DX2.5 } \\
\text { \#\# vs. } \\
\text { DC20 }\end{array}$ \\
\hline
\end{tabular}

Asterisks represent the statistical analysis in comparison to the CT group or to the indicated group at each time of different glucocorticoids' administration. ${ }^{*}$ or $\#=P<0.05$; ${ }^{* *}$ or $\# \#=P<0.01$ and ${ }^{* * *}=P<0.001$ ( $n$ per group: $\mathrm{CT}=10, \mathrm{DX} 1.25=9, \mathrm{DX} 2.5=8, \mathrm{DC} 10=10, \mathrm{DC} 20=10, \mathrm{MP} 13=8, \mathrm{MP} 6=8)$. A repeated-measures ANOVA, followed by the Bonferroni post hoc test, was used.

The results of the GA and TA weights confirm the body weight curve data with a great loss of muscle weight in the groups that received glucocorticoids in relation to the CT group $(P<0.001$ in all comparisons) (Table 2). The MP13 group showed a significantly greater muscle weight loss of GA compared to the DX2.5 and DC20 groups $(P<0.05$ and $P<0.01$, respectively), as well as in relation to the MP6 group $(P<0.001)$. The MP13 group had less TA muscle weight compared to the DC20 group $(P<0.05)$.

Table 2. Weight of collected adrenal and muscle tissues.

\begin{tabular}{cccc}
\hline \multirow{2}{*}{ Group } & \multicolumn{3}{c}{ Tissue Collected (Grams) } \\
\cline { 2 - 4 } & Adrenal & GA & TA \\
\hline CT & $0.0415 \pm 0.007$ & $2.398 \pm 0.344$ & $0.734 \pm 0.103$ \\
DX1.25 & $0.0196 \pm 0.002^{* * *}$ & $1.613 \pm 0.257^{* * *}$ & $0.512 \pm 0.038^{* * *}$ \\
DX2.5 & $0.0208 \pm 0.006^{* * *}$ & $1.774 \pm 0.275^{* * *}$ & $0.477 \pm 0.067^{* * *}$ \\
MP6 & $0.0300 \pm 0.012$ & $1.570 \pm 0.084^{* * *}$ & $0.500 \pm 0.030^{* * *}$ \\
& & $1.375 \pm 0.088^{* * *} ;$ & $0.436 \pm 0.043^{* * *} ;$ \\
MP13 & $0.0216 \pm 0.003^{* * *}$ & \#\# vs. DC20 and \# vs. & \# vs. DC20 \\
& & DX2.5 & $0.575 \pm 0.053^{* * *} ;$ \\
DC10 & $0.0311 \pm 0.013$ & $1.919 \pm 0.205^{* * *}$ & \#\# vs. MP6 and DX1.25 \\
DC20 & $0.0227 \pm 0.003^{* * *}$ & and \#s. MP6 & $0.549 \pm 0.033^{* * *}$ \\
\hline
\end{tabular}

Asterisks represent the statistical difference in comparison to the $\mathrm{CT}$ and (\#) comparison between groups. \# $=P<$ 0.05 ; \#\# $=P<0.01$ and ${ }^{* * *}=P<0.001$; ( $n$ per group: CT = 10, DX1.25 =9, DX2.5 = 8, DC10 = 10, DC20 = 10, MP13 = $8, \mathrm{MP6}=8)$

Considering the adrenal weight measurement (an indirect evaluation of HPA axis) DC10 or MP6 did not cause a significant adrenal weight loss in comparison to the CT group, as observed after the DX administration in both doses with a weight loss of approximately $51 \%(P<0.001$ to both doses in comparison to the CT group).

These data show how DX caused more negative effects to the HPA axis, even in lowest equivalent dose compared to the MP or DC; however, higher MP was more harmful to muscles or body weight than other evaluated glucocorticoids. 
3.2. Cross-Sectional Areas (CSA) and Fiber Type Proportion Resulting from Different Glucocorticoids Administration

The mATPase method was used to differentiate types 1, 2A, and $2 \mathrm{~B}$ muscle fibers, in order to evaluate how different glucocorticoids would influence CSA after 10 days of administration (Figure 2A,B).
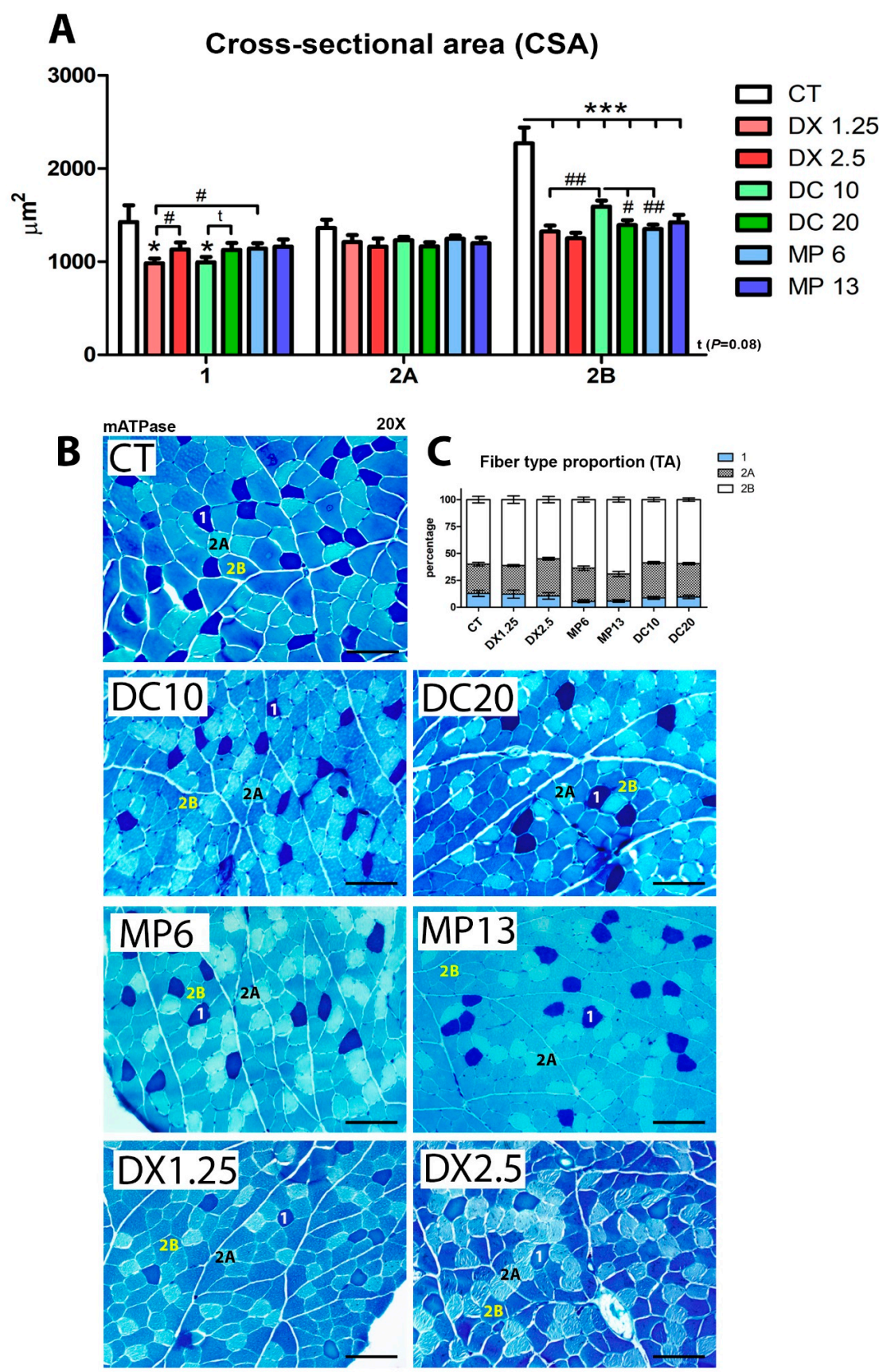

Figure 2. Muscle cross-sectional area and muscle fiber type proportions analyzed after the administration of different glucocorticoids. (A) Cross-sectional area- $\left(^{*}\right)$ represents statistical difference in comparison to the control group $(\mathrm{CT})$, and (\#) represents statistical difference between two groups. Legend: ${ }^{*}$ or \# = $P<0.05 ; \#=P<0.01$ and ${ }^{* *}=P<0.001$ ( $n$ per group: CT $=10, \mathrm{DX} 1.25=9, \mathrm{DX} 2.5=8, \mathrm{DC} 10=10$, $\mathrm{DC} 20=10, \mathrm{MP13}=8, \mathrm{MP6}=8$ ). One-way ANOVA, followed by the Bonferroni post hoc test, was used for each fiber type analysis; (B) histological mATPase photographs, scale bar $=100 \mu \mathrm{m}$; (C) muscle fiber type proportions (statistical analysis is expressed in Table 3). 
Table 3. Muscle fiber type proportion after administration of different glucocorticoids. The Mann-Whitney test was used ( $n=5$ per group).

\begin{tabular}{|c|c|c|c|c|c|c|}
\hline & Fiber 1 & $P$ Value & Fiber 2A & $P$ Value & Fiber 2B & $P$ Value \\
\hline $\mathrm{CT}$ & $12.83 \%$ & $\begin{array}{c}P=0.0040^{* *} \\
\text { vs. MP6 } \\
P=0.0213 * \\
\text { vs. MP13 }\end{array}$ & $27.17 \%$ & $\begin{array}{c}P=0.0023^{* *} \\
\text { vs. DX2.5 } \\
P=0.0180^{*} \\
\text { vs. DC } 10\end{array}$ & $60.00 \%$ & $\begin{array}{c}P=0.0296 * \\
\text { vs. MP13 }\end{array}$ \\
\hline DX1.25 & $12.18 \%$ & - & $26.50 \%$ & $\begin{array}{c}P=0.0006^{* *} \\
\text { vs. DX2.5 }\end{array}$ & $61.32 \%$ & - \\
\hline DX2.5 & $10.52 \%$ & - & $34.56 \%$ & - & $54.92 \%$ & - \\
\hline MP6 & $5.60 \%$ & $\begin{array}{c}P=0.0406^{*} \\
\text { vs. DX1.25 } \\
P=0.0464^{*} \\
\text { vs. DC10 }\end{array}$ & $30.66 \%$ & $\begin{array}{c}P=0.0652 \text { vs. } \\
\text { MP13 }\end{array}$ & $63.74 \%$ & - \\
\hline MP13 & $5.87 \%$ & - & $25.00 \%$ & $\begin{array}{c}P=0.0273^{*} \\
\text { vs. DC20 } \\
P=0.0019 * * \\
\text { vs. DX2.5 }\end{array}$ & $69.13 \%$ & $\begin{array}{c}P=0.0011^{* *} \\
\text { vs. DX2.5 } \\
P=0.0010^{* *} \\
\text { vs. DC20 }\end{array}$ \\
\hline DC10 & $8.72 \%$ & - & $32.60 \%$ & - & $58.69 \%$ & - \\
\hline DC20 & $9.54 \%$ & - & $31.03 \%$ & - & $59.43 \%$ & - \\
\hline
\end{tabular}

The CSA of type 1 fibers decreased only on the DX1.25 and DC10 groups (fewer doses) in comparison to the CT $(P<0.05$ to both) and in comparison to the higher dose groups DX2.5 $(P<0.05)$ and DC20 $(P=0.09)$. MP at both doses did not cause significant changes in type 1 muscle fibers.

None of the glucocorticoids in either doses led to changes in 2A muscle fibers in comparison to the CT.

In type 2B fibers, a significant CSA decrease was observed in all groups in comparison to the CT group $(P<0.001$ for all). However, among the glucocorticoid groups, there was an important variation: Animals of the DC10 group had a higher CSA of 2B fibers in comparison to the higher dose group, DC20 $(P<0.05)$, and the equipotent doses groups, DX1.25 and MP6 $(P<0.01$ for both).

In order to evaluate the muscle fiber type transition after 10 days of different glucocorticoid administration, we calculated the proportion of muscle fibers (Figure 2C) classified from a pool of 500 muscle fibers per animal.

We observed a significant decrease in the proportion of type 1 muscle fibers in both groups receiving MP (MP13 and MP6) in relation to the CT group $(P<0.01$ and $P<0.05$, respectively). The proportion of type 1 fibers in the MP6 group was significantly lower than in the equipotent dose groups DX1.25 and DC10 ( $P<0.05$ for both).

In type 2A muscle fibers, there was a significant increased proportion in the DX2.5 $(P<0.01)$ and DC10 $(P<0.05)$ groups compared to the CT group. A significant difference was found when comparing the DX2.5 group to the DX1.25 group $(P<0.01)$. It was observed that the MP13 group presented the lowest proportion of $2 \mathrm{~A}$ fibers in relation to the other groups, DX2.5 $(P<0.01)$ and DC20 $(P<0.05)$.

In type $2 \mathrm{~B}$ muscle fibers, the MP13 group showed the highest proportion of fibers in relation to the CT group $(P<0.05)$, and compared to the other groups, DX2.5 $(P<0.01)$ and DC20 $(P<0.01)$.

These data show that MP at both doses significantly affects the muscle fiber switching program (slow-to-fast) during muscle atrophy more than other glucocorticoids. Additionally, DX and DC at lower doses are more harmful to the type 1 fiber CSA than higher doses. 


\subsection{IGF-1 and Atrogenes Expression Resulting from Different Glucocorticoids Administration}

Considering the importance of the IGF-1/PI-3k/Akt/mTOR pathway in the muscle atrophy process, we analyzed its three main components: Total and phosphorylated forms, (Akt, GSK-3 $\beta$, and FoxO3a) protein expression by Western blotting (Figure 3), and atrogenes mRNA expression (related to the FoxO transcriptional activity and ubiquitin-proteasome system) by quantitative PCR (Figure 4).
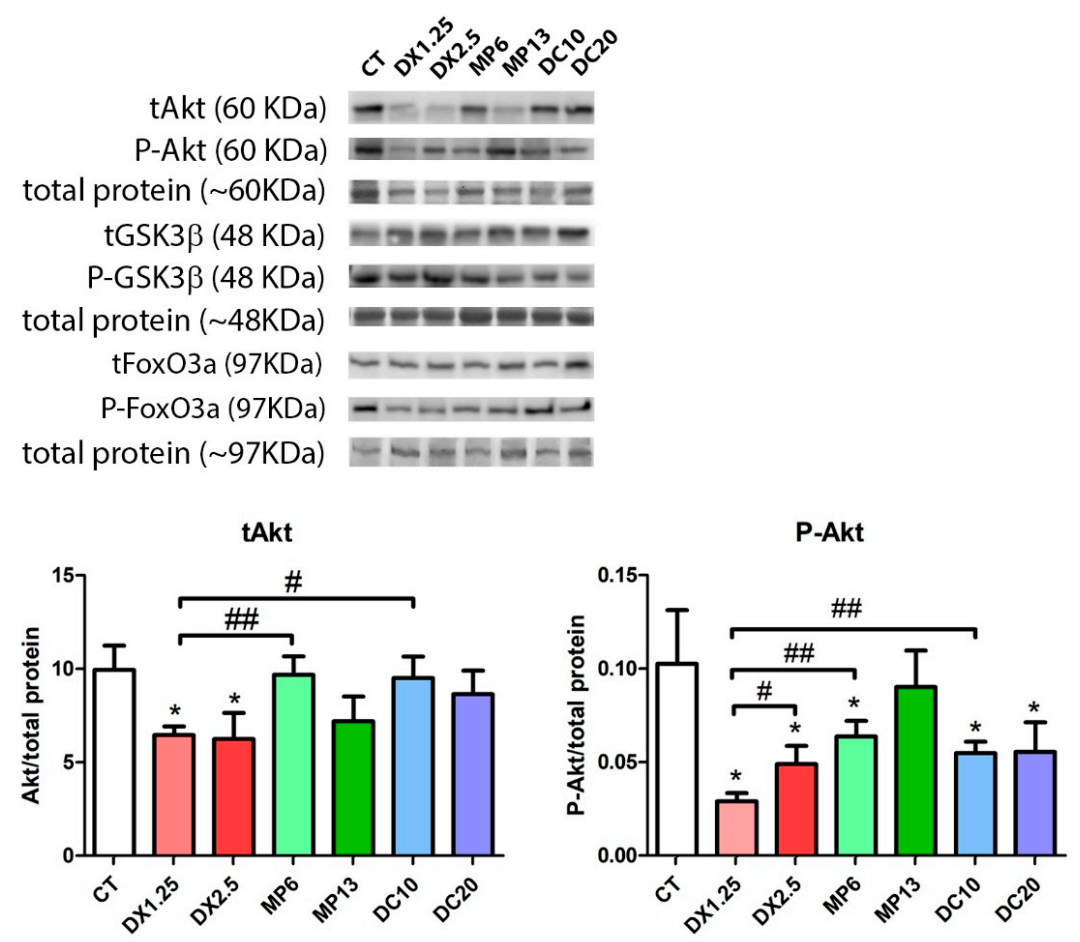

total GSK-3 $\beta$

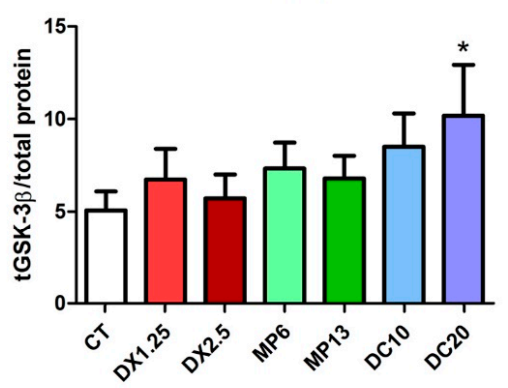

P-GSK-3 $\beta$

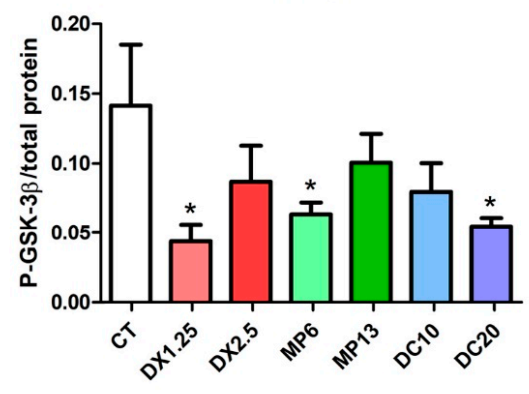

tFOXO3a

P-FOXO3a
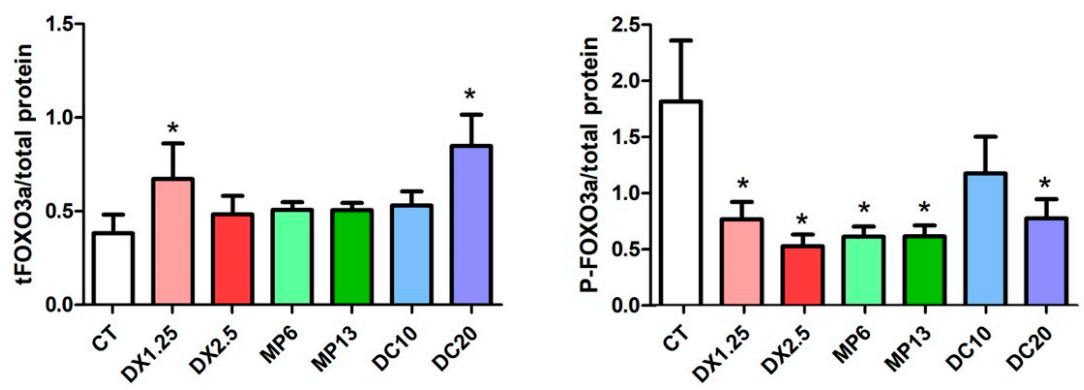

Figure 3. Western blotting analysis of the IGF-1 pathway after administration of different glucocorticoids. ${ }^{*}$ ) represents the statistical difference in comparison to the CT and (\#) represents statistical difference between groups. Legend: ${ }^{*}$ or $\#=P<0.05 ; \#=P<0.01$ ( $n$ per group: CT = 10, DX1.25 = 9, DX2.5 = 8, $\mathrm{DC} 10=10, \mathrm{DC} 20=10, \mathrm{MP} 13=8, \mathrm{MP} 6=8$ ). 
A

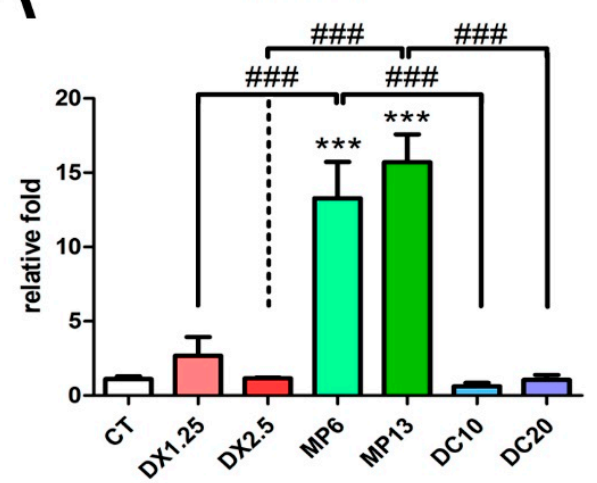

M YOSTATIN

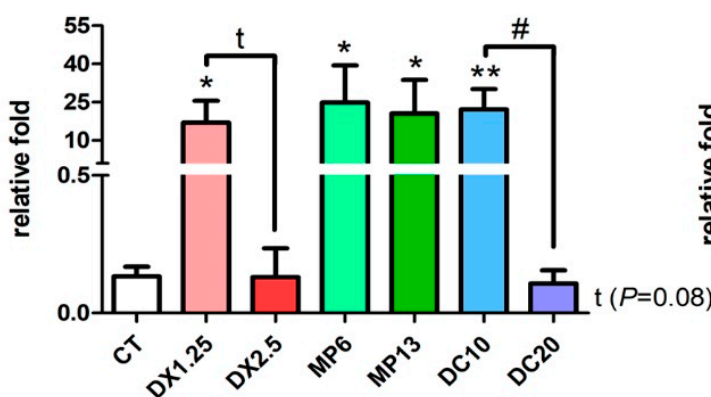

$\mathrm{E}$

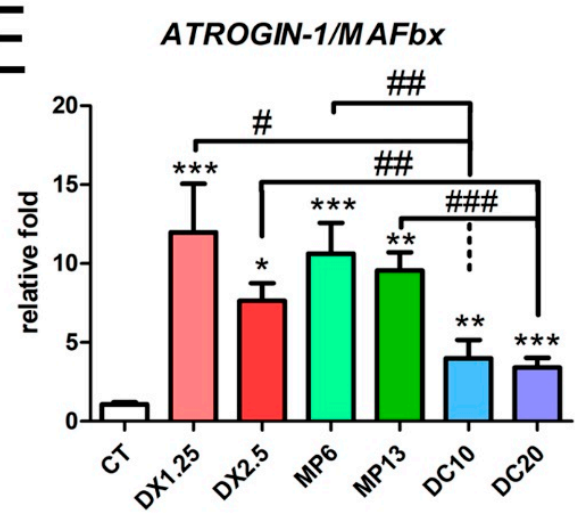

B REDD-2

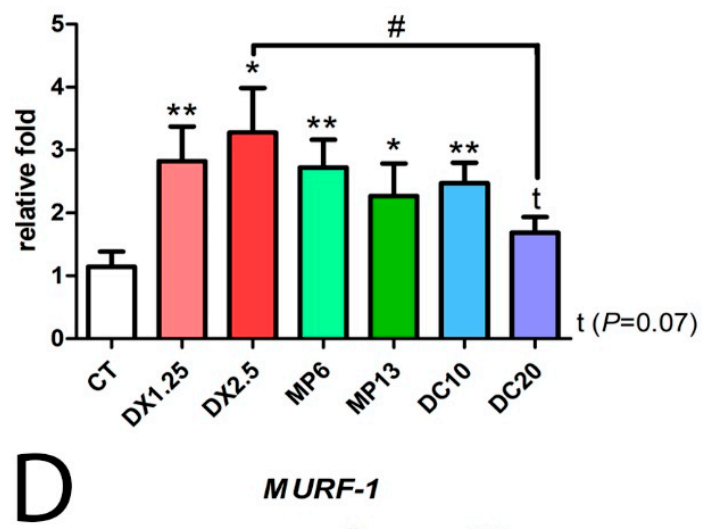

$\mathrm{F}$

GAPDH

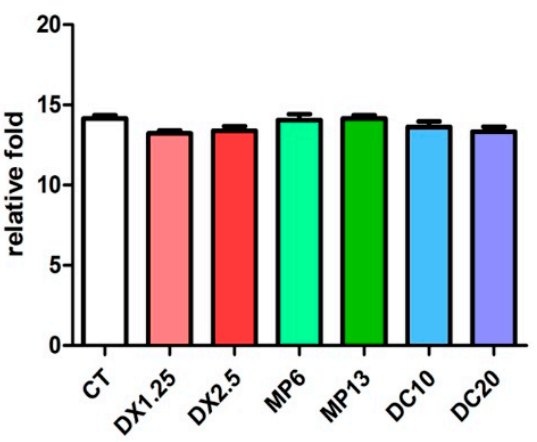

Figure 4. mRNA expression by RT-PCR of MURF-1, Atrogin-1/MAFbx, REDD-1, REDD-2 and MYOSTATIN after administration of different glucocorticoids. Atrogenes expression (A-E), Myostatin expression $(\mathbf{C})$, housekeeping gene expression GAPDH $\left.(\mathbf{F}) .{ }^{*}\right)$ represents the statistical difference in comparison to the $\mathrm{CT}$, and (\#) represents statistical difference between groups. Legend: ${ }^{*}$ or $\#=P<$ 0.05 ; ${ }^{* *}$ or \#\# $=P<0.01$ and ${ }^{* * *}$ or \#\#\# $=P<0.001$. ( $n$ per group: CT = 10, DX1.25 = 9, DX2.5 = 8, DC10 $=10, \mathrm{DC} 20=10, \mathrm{MP} 13=8, \mathrm{MP6}=8$ ).

We observed that the expression of total Akt in animals receiving DX1.25 and 2.5 was significantly lower in comparison to the CT group $(P<0.05$ for both) and, in comparison, to the DC10 $(P<0.05)$ and MP6 $(P<0.01)$ groups. No differences were observed between the higher dose groups compared to the lower dose groups receiving DX. In the expression of P-Akt, a significant decrease was observed in all groups in relation to the CT group, except the MP13 group, with a significant decrease in the DX1.25 group compared to other glucocorticoid groups.

The expression of total GSK3 $\beta$ showed that only animals from the DC20 group had a significant increase in comparison to the CT group $(P<0.05)$. The expression of P-GSK3 $\beta$ (Ser9) significantly 
decreased in the DX1.25, MP6, and DC20 groups in comparison to the CT group ( $P<0.05$ for all). No differences among glucocorticoid groups were found in GSK3 $\beta$ and P-GSK3 $\beta$ expressions.

The expression of total FOXO3a showed a significant increased expression in the DC20 and DX1.25 groups in comparison to the CT group $(P<0.05)$. A significant decrease in the P-FOXO3a (Ser253) expression was observed in all groups compared to the $\mathrm{CT}$ group, except in the DC10 group. No difference was observed among glucocorticoid groups.

The expression of REDD-1 was significantly increased only in the groups receiving MP (the MP6 and MP13 groups) compared to the CT group and DX1.25 and DX2.5 groups $(P<0.001$ in all comparisons) (Figure 4A). Nevertheless, the expression of REDD-2 (Figure 4B) was significantly increased in all groups, but with a tendency to increase in the DC20 group $(P=0.07)$, compared to the CT group. For the REDD-2 expression, there was a significant difference between the groups DX2.5 and DC20 $(P<0.05)$.

The MYOSTATIN expression significantly increased in all groups, except in the DX2.5 and DC20 groups, in comparison to the CT group (Figure $4 \mathrm{C}$ ). There was a significantly higher expression comparing the DC10 and DC20 groups $(P<0.05)$.

The $M u R F-1$ expression significantly increased in all groups receiving DX and MP in comparison to the CT group, without changes in the DC10 or DC20 group (Figure 4D). There was a significant increase in the MuRF-1 expression in the MP13 group when compared to the DX2.5 $(P<0.05)$ and DC20 $(P<0.001)$ groups, as well as comparing the MP6 group and the equipotent dose groups (DX1.25, $P<0.01$ and DC10, $P<0.001)$.

The Atrogin-1 expression (Figure 4E) significantly increased in all groups in comparison to the CT group. The DC10 and DC20 groups showed the lowest Atrogin-1 expression in comparison to the other glucocorticoids: DC10 vs. MP6 $(P<0.01)$ and vs. DX1.25 $(P<0.05)$, DC20 vs. MP13 $(P<0.001)$ and vs. DX2.5 $(P<0.01)$.

These data showed that DX has a greater effect on the AKT total and phosphorylated state, and MP displayed higher atrogenes (REDD-1 and MURF-1) expression in comparison to the other glucocorticoids.

\subsection{Insulin Receptor Substrate 1/2 Gene Expression Resulting from Different Glucocorticoids Administration}

In an exploratory way, we evaluated the expression of insulin receptor substrates (IRS-1 and IRS-2) because of their relation to the response of several hormones and cytokines receptors such as IL-4-R, IL-9-R, IFNy-R, GH-R, IFN $\alpha$ as well as the insulin and IGF-1 receptor [34] (Figure 5).
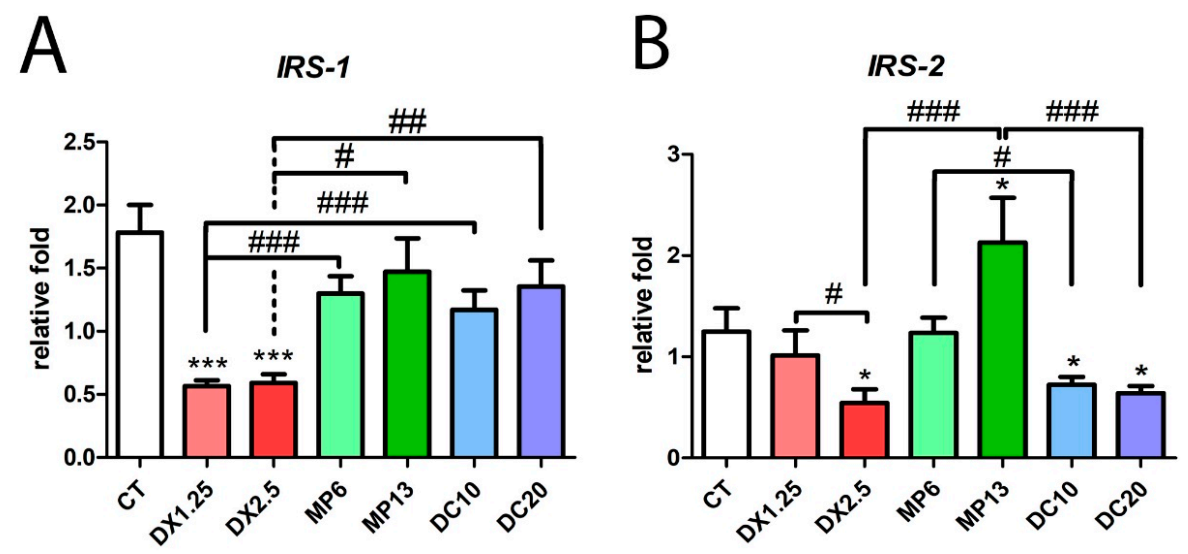

Figure 5. mRNA expression by RT-PCR of IRS-1 (A) and IRS-2 (B) after the administration of different glucocorticoids. ${ }^{*}$ ) represents the statistical difference in comparison to the CT and (\#) represents statistical difference between groups. Legend: ${ }^{*}$ or $\#=P<0.05$; \#\# $=P<0.01$ and ${ }^{* * *}$ or $\# \#=P<0.001$. ( $n$ per group: $\mathrm{CT}=10, \mathrm{DX} 1.25=9, \mathrm{DX} 2.5=8, \mathrm{DC} 10=10, \mathrm{DC} 20=10, \mathrm{MP} 13=8, \mathrm{MP} 6=8$ ). 
IRS-1 mRNA expression significantly decreased in the DX1.25 and DX2.5 groups in comparison to the CT group ( $P<0.001$ to both) and to other glucocorticoids. IRS-2 expression significantly decreased only in the groups DX2.5, DC10, and DC20 in comparison to the CT group $(P<0.05$ for all), and between the DX1.25 and DX2.5 groups $(P<0.05)$. Interestingly, the MP13 group had an increased IRS-2 in comparison to the CT group $(P<0.05)$ and equipotent glucocorticoids DX2.5 and DC20 $(P<0.001$ to both).

These data show that 10 days of DX administration is more likely to affect multiple inflammatory, myogenic and insulin response pathways than other glucocorticoids in both dosages.

\subsection{Methylprednisolone Administration Leads to An Inversion of Myogenic mRNA Expression}

Considering the impact of glucocorticoids upon the myogenic program, we evaluated the mRNA expression of $M y o G$ and $M y o D$ by a quantitative PCR (Figure 6).
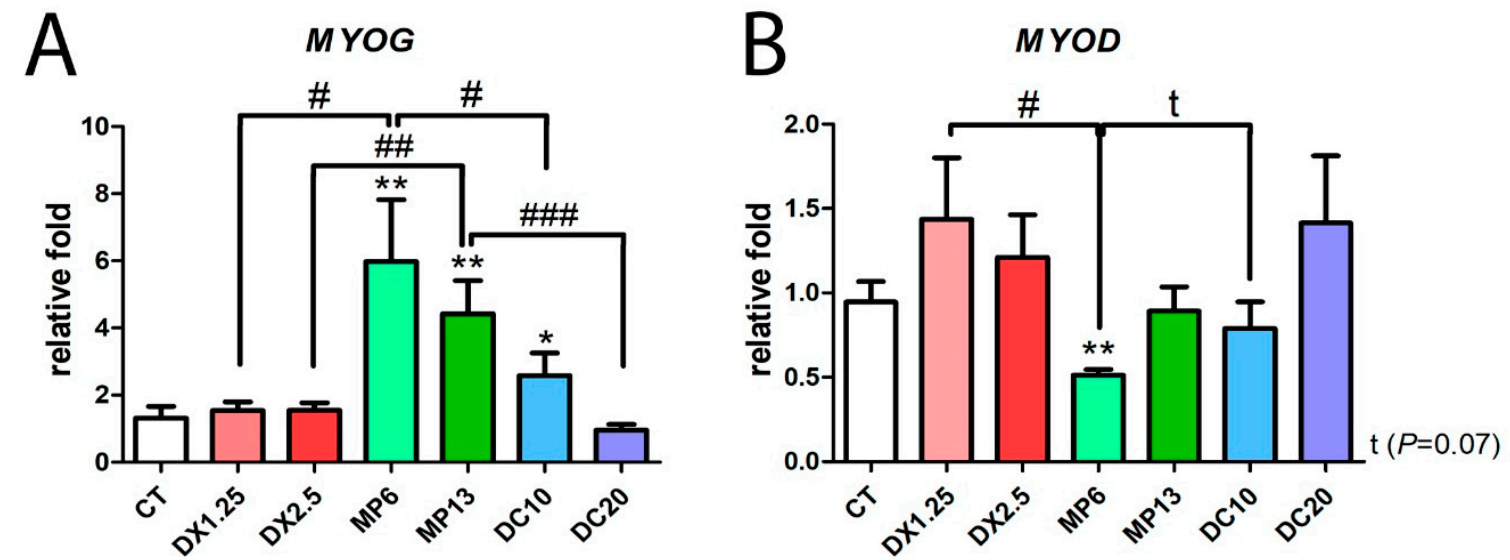

Figure 6. mRNA expression by RT-PCR of $M y o G(\mathbf{A})$ and $M y o D(B)$ after the administration of different glucocorticoids. ${ }^{*}$ ) represents the statistical difference in comparison to the $\mathrm{CT}$, and (\#) represents statistical difference between groups. Legend: ${ }^{*}$ or $\#=P<0.05$; ${ }^{* *}$ or $\# \#=P<0.01$ and \#\#\# $=P<0.001$. ( $n$ per group: $\mathrm{CT}=10, \mathrm{DX} 1.25=9, \mathrm{DX} 2.5=8, \mathrm{DC} 10=10, \mathrm{DC} 20=10, \mathrm{MP} 13=8, \mathrm{MP} 6=8$ ).

Between glucocorticoids, MyoG expression was increased only in the groups receiving methylprednisolone (MP6 and MP13) and in the DC10 group compared to the CT group (Figure 6A). This increase in the expression of MyoG in the MP6 and MP13 groups was significant in comparison to the other groups: MP6 vs. DX1.25 and DC10 ( $P<0.05$ for both); MP13 vs. DX2.5 $(P<0.01)$ and vs. DC20 $(P<0.001)$.

The expression of MyoD decreased only in the MP6 group in comparison to the CT group $(P<0.01)$ and in the other groups with equipotent dose, DX1.25 and DC10 ( $P<0.05$ for both) (Figure 6B).

These data showed that MP administration leads to an inversion of myogenic mRNA expression during the atrophic process.

\subsection{MEK/ERK Pathway Changes Resulting from Different Glucocorticoids Administration}

We aimed to identify the influence of different glucocorticoids on the expression of ERK components once there is a possible positive effect of the Ras/Raf/MEK/ERK pathway on muscle fiber type switching [35]. Therefore, a negative regulation of MEK/ERK would cause major changes in fiber switching (fast-to-slow).

No differences regarding the expression of the total ERK1/2 was observed between the groups (Figure 7). Considering the phosphorylated forms of ERK1/2 (Thr202/Tyr204), a significant decrease of the P-ERK1 and P-ERK2 expression was observed in the DX2.5, MP6, and MP13 groups in comparison to the CT group. There was a significantly lower expression in the MP6 group in comparison to 
equipotent doses within the DX1.25 and DC10 groups $(P<0.01$ and $P<0.05$, respectively) in both P-ERK1/2 expressions.
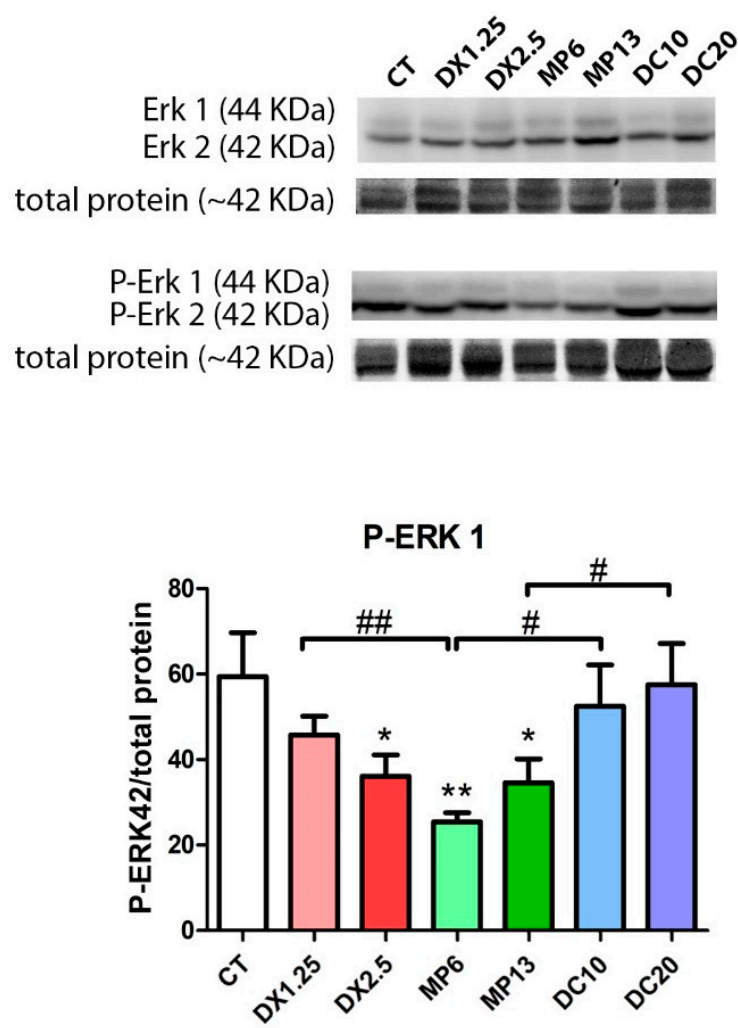

ERK total

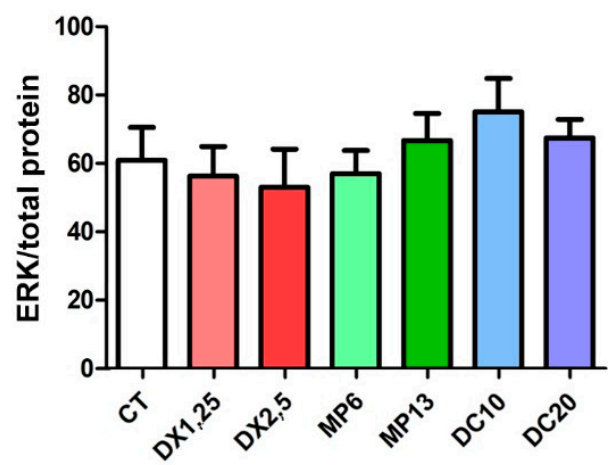

P-ERK 2

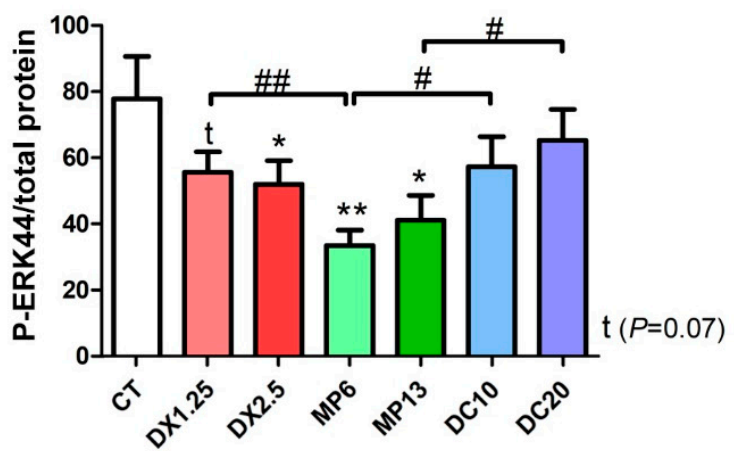

Figure 7. Western blotting analysis of the Ras/Raf/MEK/ERK pathway after the administration of different glucocorticoids. $\left(^{*}\right)$ represents the statistical difference in comparison to the CT and (\#) represents statistical difference between groups. Legend: ${ }^{*}$ or $\#=P<0.05$; ${ }^{* *}$ or $\# \#=P<0.01$ (n per group: $\mathrm{CT}=10, \mathrm{DX} 1.25=9, \mathrm{DX} 2.5=8, \mathrm{DC} 10=10, \mathrm{DC} 20=10, \mathrm{MP} 13=8, \mathrm{MP} 6=8$ ).

These data showed that MP significantly affects P-ERK1/2 signalization more than other glucocorticoids, and it is possibly related to fiber type transition.

\section{Discussion}

Our study evaluated the impacts of different commonly used glucocorticoids upon healthy skeletal muscle by evaluating the cross-sectional areas of the fibers, muscle fiber type transition, main pathways related to the muscle trophism, and genes related to the muscle atrophy.

The doses of DX administered ( 2.5 and $1.25 \mathrm{mg} / \mathrm{kg} / \mathrm{day}$ ) consistently caused body weight loss, as well as muscle and adrenal weight decrease as expected and showed by others [29]. However, compared to the other glucocorticoids, we observed that MP at a dosage of $13 \mathrm{mg} / \mathrm{kg} /$ day was more harmful to the body and muscle weight compared to DX and DC. At a low dose comparison, the study of Dekhuijzen et al. (1995) showed that DC can cause more damage to skeletal muscle and body weight than MP in animals receiving both at low doses $(0.5 \mathrm{mg} / \mathrm{kg} /$ day for six weeks) [27]. Otherwise, as observed in the study by Nava, et al. [36], high doses of MP ( $80 \mathrm{mg} / \mathrm{kg} /$ day) significantly affects body weight (on the 3rd day) and muscle at the end of five days of administration. Therefore, there is a dose-influence of both glucocorticoid types, deflazacort and methylprednisolone, administered on the muscle tissue. In the first study [27] was observed that the DC, in addition to the decrease in body/muscle weight, causes higher muscular atrophy in fibers types $1,2 \mathrm{~A}$, and $2 \mathrm{~B}$ in comparison to the MP and control animals. The authors used a dose of $0.4 \mathrm{mg} / \mathrm{kg} / \mathrm{day}$ of deflazacort for six weeks, a dose several times lesser than used on this study (20 and $10 \mathrm{mg} / \mathrm{kg} /$ day). 
The study by Yoshimura, et al. [37], revealed an extensive atrophy of several skeletal muscles types in healthy beagles after a low dose administration $(0.9 \mathrm{mg} / \mathrm{kg} /$ day) of DC (for three months). In our study, a dose of $10 \mathrm{mg} / \mathrm{kg} /$ day caused less pre- and post-drug weight loss among glucocorticoids (15.5\%); however, it caused a great muscular atrophy impact in type 1 fibers (CSA) in relation to its comparative group (DC20) and MP at $6.7 \mathrm{mg} / \mathrm{kg} /$ day. The muscle atrophy observed in type 1 fibers in animals receiving lower doses of DC or DX, rather than at twice the dose, was unexpected. However, studies using different doses of glucocorticoids also observed greater muscular atrophy (diaphragmatic) in animals receiving lower doses of glucocorticoid in comparison to those receiving higher doses. Maes et al. (2008), showed that the administration of MP in doses between 30 and $80 \mathrm{mg} / \mathrm{kg} /$ day for $24 \mathrm{~h}$ in rats caused attenuation of the effects of diaphragmatic dysfunction during mechanical ventilation without impact on the fiber area [38]. However, the use of a lower dose $(5 \mathrm{mg} / \mathrm{kg} /$ day) led to a significant impairment of the diaphragmatic muscle [39]. The authors postulated that high-dose glucocorticoid would be able to inhibit calpain activity, reducing protein degradation and, thus, protecting the fiber loss of the cross-sectional area, which was not measured in this study, but that could certainly explain the variable dose-dependency of the muscle atrophy by the different glucocorticoids available.

Considering that there was no excessive body weight loss that could justify a possible influence in the CSA results of DC group, it was clear that the DC in smaller doses has less of an impact on type $2 B$ fibers than MP and DX, on the other hand with more effect on type 1 fibers (as also observed in the lower-dose DX group). This finding might be related to the supposed calpain inhibition in high doses, as postulated before; however, with a plausible "fiber-specificity" effect since it was only observed in type 1 fibers in our study and in the diaphragmatic muscles by other authors [38,39], which is a musculature with a great proportion of oxidative fibers.

Regarding the adrenal gland weight, DC at a dose of $10 \mathrm{mg} / \mathrm{kg} /$ day and MP at a dose of $6.7 \mathrm{mg} / \mathrm{kg} /$ day for 10 days did not negatively influence the adrenal gland weight as observed with DX at both doses. Therefore, in short periods DX is more harmful to the trophism of the adrenal gland (HPA axis) than other glucocorticoids at the same dose equivalency, possibly due to stronger inhibitory activity under the HPA axis, corticotrophin releasing hormone (CRH) and hence adrenocorticotropic hormone (ACTH) [40,41].

At higher doses both drugs, methylprednisolone and deflazacort, similarly influenced adrenal weight when compared to DX. In the study by Dekhuijzen et al. (1995) [27], a low-dose administration of DC $(0.5 \mathrm{mg} / \mathrm{kg} /$ day) or MP at a dose of $0.4 \mathrm{mg} / \mathrm{kg} /$ day for a longer period (six weeks) was sufficient to significantly decrease the weight of the rats' adrenal gland. This indicates that low doses of both of the glucocorticoids do not influence adrenal trophism following administration of up to 10 days, but it can significantly affect their trophism if administered chronically in rats.

Nava et al. (1996), observed a significant decrease in the adrenal gland weight ( $25 \%$ decrease) of rats receiving MP at a dose of $80 \mathrm{mg} / \mathrm{kg} /$ day for seven days [36]. However, in our study, we observed a $47.8 \%$ decrease in the adrenal weight of the MP13 group compared to the CT group, almost twice of that observed by the authors using a much lower dose. This outcome points to a possible "protective mechanism" by the HPA axis at an extremely high dose of glucocorticoid, possibly by receptor sensitivity regulation, transcription, post-translational modification, or feedback.

It is known that Akt, once activated by IGF-1 by phosphorylation, leads to the activation/inhibition of several proteins, acting on the activation of mTOR, to increasing protein synthesis, and the inhibition of GSK3 $\beta$, related to glucose metabolism and insulin action, which detracts from muscle synthesis [42-46].

Unlike other studies, our research indicated that the DX glucocorticoid was able to cause a significant decrease in the total Akt expression. However, considering AKT phosphorylation, all glucocorticoids decreased its expression, along with FoxO3a phosphorylation. Such outcomes support the literature affirming that glucocorticoids directly affect the IGF-1 pathway, causing inhibitory effects on the phosphorylation of Akt, which leads to a decreased protein synthesis and increased protein degradation [11,47]. Considering the glucocorticoid effects on inflammatory response inhibition as 
well as the IGF-1 and glucose uptake (peripheral insulin resistance), the IRS-1 mRNA expression was only affected by dexamethasone (1.25 and $2.5 \mathrm{mg} / \mathrm{kg} /$ day for 10 days), probably leading to a significant impairment of insulin signaling, although we have not evaluated IRS1/2 protein expression, insulin production, glycaemia, or muscle glucose uptake. Studies have already shown that DX is able to decrease IRS-1 signaling through competition by the active glucocorticoid receptor for the P85 $\alpha$ (substrate of the insulin receptor) impairing insulin, IGF-1 and ERK signaling [48,49].

The REDD1/2 (regulated in development and DNA damage responses 1/2) is a component related to the stress response and is activated by the use of glucocorticoids and reactive oxygen species [50-52]. However, the oxidative stress produces atrophy principally via activation of p38 mitogen activated protein kinase (MAPK), which subsequently induces the expression of MAFbx, MuRF1 and autophagy-lysosome system [18,53]. Studies have shown that there is a time-dependent muscle response of $R E D D-1$ and $R E D D-2$ after glucocorticoid exposure [54-57], where the REDD-1 expression is initially elevated (first 24-48 s), but normalizes after few days accompanied by an increased REDD-2 expression. Recapitulating the observations in our study, all groups of animals receiving any drug/dose showed an elevated REDD-2 expression, however, only animals receiving MP (both doses) had significantly increased expressions of REDD-1 in comparison to the other groups of glucocorticoid.

One of the inhibitory effects upon mTORC1 activity occurs through the action of REDD1 and REDD2, produced by the transcription factor FoxO3, that inhibits the action of the Rheb protein on mTOR activation affecting muscle protein synthesis [56,58]. Interestingly, Frost, et al. [59], have shown that the IGF-1 administration (in vitro and in vivo) caused an increased REDD1 (mRNA and protein) expression without affecting protein synthesis, yet, this finding has not yet been confirmed. Similarly, the animals from the MP group displayed an increased REDD1 expression associated with the high $M y o G$ expression (late myogenic program) and decreased $M y o D$ (early myogenic program), and this outcome is not elucidated. Although the protein synthesis are remarkably affected by glucocorticoids $[11,18,60]$, our efforts were directed toward the muscle atrophy impact and muscle synthesis-related proteins (e.g., P70 $56 \mathrm{~K}$, EIFs, 4EBP1 and mTOR) were not evaluated, but certainly would clarify the methylprednisolone effect on both mRNA and protein related to protein synthesis in comparison to other glucocorticoids.

The same studies have shown that glucocorticoids have an effect of decreasing the muscle $\mathrm{Ca}^{2+}$ influx in a lesser or greater degree, depending on the type of glucocorticoid [61]. Despite a lack of studies comparing the $\mathrm{Ca}^{2+}$ influx between these glucocorticoids, it is known that calcium levels can positively influence the Ras/Raf/MEK/ERK pathway signaling [62]. Based on this understanding, we believe that the decrease in the P-ERK1/2 expression observed in the administration of the MP might have occurred due to alterations in the level of sarcoplasmic calcium. Such an effect would cause greater damage to an early myogenic program compared to other glucocorticoids and changes of muscle fiber proportion because ERK1/2 is related to protein synthesis, neuromuscular junctions maintenance, and fiber type switching (fast $\rightarrow$ slow) $[35,63,64]$. Corroborating to studies describing that besides anti-inflammatory properties, the glucocorticoids are also described by its ability to enhance mitochondrial biogenesis and to increase the proportion of type 1 muscle fibers [24], in which oxidative metabolism is predominant, with a significantly higher concentration of glucocorticoid receptor sites in the slow-fiber soleus muscle as compared with the fast-fiber extensor digitorum longus muscle [65].

Glucocorticoid administration induces an increase in Myostatin expression with a consequent increase in the protein and gene expression of Atrogin-1/MAFbx and MuRF-1 enzymes, mediated by FoxO3a and Smad2/3, leading to the start of the muscle atrophy process $[19,47,66,67]$.

In our study, the expression of Myostatin was lower in groups receiving high doses of DX and DC (in comparison to lower doses), which may be related to a dose/time-dependence response of the exposed tissue to glucocorticoids [68,69]. All groups showed a significant increase of the MURF-1 expression, except in the groups receiving DC. Significantly lower Atrogin-1 expression was observed in the DC groups in comparison to the other glucocorticoid groups. These findings point to a milder effect on the expression of atrogenes by DC. 
The expression of P-FOXO3a (a transcription factor responsible for the translation of the atrogenes MuRF-1 and Atrogin-1) was similar between the groups. However, the gene and protein expression of atrogenes may show different results, as already described by Wang, et al. [70].

DC has been studied since the 1980s, and several factors have determined it as safer than other glucocorticoids. These findings are based on pharmacological properties, such as a lower excretion of calcium and hydroxyproline (amino acid present in collagen and abundant in the bone matrix), a lower effect on glucose metabolism and neuronal degeneration [71], lower effect on bone metabolism [72], and helping in preventing body fat accumulation and body growth retardation [73]. However, few studies have employed its use in healthy specimens evaluating muscle molecular pathways, and our study is more exploratory regarding this consideration. It is worth noting that DC is a compound that is mainly prescribed for the treatment of Duchenne's muscular dystrophy (DMD) to bring benefic outcomes to treated patients. However, DC is associated with many side effects comparable to prednisolone/prednisone $[74,75]$ and it was only released for use in the United States in February 2017 to treat DMD patients who are five years old or older (FDA note available at https:/www.fda.gov/NewsEvents/Newsroom/PressAnnouncements/ucm540945.htm).

In our study the DC's short-term effect on muscle atrophy, specifically in type 2B muscle fibers, and the lower atrogenes expression (Atrogin-1/MAFbx and MuRF-1), lead us to consider this compound as safer in a equipotent comparison between other glucocorticoids, despite the long-term effects, which can be similar or worse to other compounds, depending on the dose and days of administration.

Summarizing, we concluded that DC has a milder effect upon type 2B muscle atrophy and atrogenes expression, nevertheless, it boosts type 1 muscle fiber atrophy. Surprisingly, the lower doses of DC and DX are more harmful to slow-switch fibers CSA than the higher amounts.

MP interferes more with the body/peripheral muscles mass, myogenic program, muscle fiber type transition, and MEK/ERK pathway than the other glucocorticoids. In addition, DX is more harmful to the HPA axis and IGF-1 pathway (Akt/FoxO expressions) than DC and MP. Based on these assumptions, additional studies using equivalency will be useful to understand the action of glucocorticoids in the skeletal muscle as well as other tissues. This translational approach can drive to treatments more specific to the clinical goals, but considering other homeostatic processes that coexist.

Author Contributions: A.F., project design, animal treatment, bench experimentations, data analysis, draft of manuscript, final review, and submission; J.d.C.N., animal treatment, bench experimentation, and review of the manuscript; L.N.S., animal treatment and bench experimentation; P.V.M.e.S., animal treatment, and bench experimentation; G.Y.S., animal treatment, and bench experimentation; T.P.C.B., bench experimentation; G.C., final review of the manuscript, and coordination; E.Z., Project design, data analysis, coordination, and final review of the manuscript.

Funding: A.F. was sponsored by São Paulo Research Foundation (FAPESP - Fundação de Amparo à Pesquisa do Estado de São Paulo)—Process \#2013/23191-6. This publication was funded by FAPESP process \#2019/08527-4.

Conflicts of Interest: The authors declare no conflict of interest.

\section{References}

1. Barnes, P.J. Glucocorticoids. Chem. Immunol. Allergy. 2014, 100, 311-316. [CrossRef] [PubMed]

2. Davies, E.; MacKenzie, S.M. Extra-adrenal production of corticosteroids. Clin. Exp. Pharmacol. Physiol. 2003, 30, 437-445. [CrossRef]

3. Taves, M.D.; Gomez-Sanchez, C.E.; Soma, K.K. Extra-adrenal glucocorticoids and mineralocorticoids: Evidence for local synthesis, regulation, and function. Am. J. Physiol. Endocrinol. Metab. 2011, 301, E11-E24. [CrossRef] [PubMed]

4. Chrousos, G.P.; Charmandari, E.; Kino, T. Glucocorticoid action networks-An introduction to systems biology. J. Clin. Endocrinol. Metab. 2004, 89, 563-564. [CrossRef] [PubMed]

5. Amon, A.; Brune, K.; Pahl, A. The anti-inflammatory action of glucocorticoids and PDE4-inhibitors is mediated in part by modulation of MAPK signaling pathways. N-S Arch. Pharmacol. 2005, 371, R72. 
6. Nicolaides, N.C.; Charmandari, E.; Chrousos, G.P.; Kino, T. Recent advances in the molecular mechanisms determining tissue sensitivity to glucocorticoids: Novel mutations, circadian rhythm and ligand-induced repression of the human glucocorticoid receptor. BMC Endocr. Disord. 2014, 14. [CrossRef]

7. Birnkrant, D.J.; Bushby, K.; Bann, C.M.; Apkon, S.D.; Blackwell, A.; Brumbaugh, D.; Case, L.E.; Clemens, P.R.; Hadjiyannakis, S.; Pandya, S.; et al. Diagnosis and management of Duchenne muscular dystrophy, part 1: Diagnosis, and neuromuscular, rehabilitation, endocrine, and gastrointestinal and nutritional management. Lancet Neurol. 2018, 17, 251-267. [CrossRef]

8. Moxley, R.T., 3rd; Pandya, S.; Ciafaloni, E.; Fox, D.J.; Campbell, K. Change in natural history of Duchenne muscular dystrophy with long-term corticosteroid treatment: Implications for management. J. Child. Neurol. 2010, 25, 1116-1129. [CrossRef]

9. Houde, S.; Filiatrault, M.; Fournier, A.; Dube, J.; D'Arcy, S.; Berube, D.; Brousseau, Y.; Lapierre, G.; Vanasse, M. Deflazacort use in Duchenne muscular dystrophy: An 8-year follow-up. Pediatr. Neurol. 2008, 38, 200-206. [CrossRef]

10. Schacke, H.; Docke, W.D.; Asadullah, K. Mechanisms involved in the side effects of glucocorticoids. Pharmacol. Therapeut. 2002, 96, 23-43. [CrossRef]

11. Schakman, O.; Kalista, S.; Barbe, C.; Loumaye, A.; Thissen, J.P. Glucocorticoid-induced skeletal muscle atrophy. Int. J. Biochem. Cell Biol. 2013, 45, 2163-2172. [CrossRef] [PubMed]

12. Gupta, A.; Gupta, Y. Glucocorticoid-induced myopathy: Pathophysiology, diagnosis, and treatment. Indian J. Endocrinol. Metab. 2013, 17, 913-916. [CrossRef] [PubMed]

13. Gordon, B.S.; Kelleher, A.R.; Kimball, S.R. Regulation of muscle protein synthesis and the effects of catabolic states. Int. J. Biochem. Cell Biol. 2013, 45, 2147-2157. [CrossRef]

14. Bentzinger, C.F.; Romanino, K.; Cloetta, D.; Lin, S.; Mascarenhas, J.B.; Oliveri, F.; Xia, J.; Casanova, E.; Costa, C.F.; Brink, M.; et al. Skeletal muscle-specific ablation of raptor, but not of rictor, causes metabolic changes and results in muscle dystrophy. Cell Metab. 2008, 8, 411-424. [CrossRef] [PubMed]

15. Brugarolas, J.; Lei, K.; Hurley, R.L.; Manning, B.D.; Reiling, J.H.; Hafen, E.; Witters, L.A.; Ellisen, L.W.; Kaelin, W.G., Jr. Regulation of mTOR function in response to hypoxia by REDD1 and the TSC1/TSC2 tumor suppressor complex. Genes Dev. 2004, 18, 2893-2904. [CrossRef] [PubMed]

16. Sandri, M.; Lin, J.; Handschin, C.; Yang, W.; Arany, Z.P.; Lecker, S.H.; Goldberg, A.L.; Spiegelman, B.M. PGC-1alpha protects skeletal muscle from atrophy by suppressing FoxO3 action and atrophy-specific gene transcription. Proc. Natl. Acad. Sci. USA 2006, 103, 16260-16265. [CrossRef]

17. Shimizu, N.; Yoshikawa, N.; Ito, N.; Maruyama, T.; Suzuki, Y.; Takeda, S.; Nakae, J.; Tagata, Y.; Nishitani, S.; Takehana, K.; et al. Crosstalk between glucocorticoid receptor and nutritional sensor mTOR in skeletal muscle. Cell Metab. 2011, 13, 170-182. [CrossRef]

18. Braun, T.P.; Marks, D.L. The regulation of muscle mass by endogenous glucocorticoids. Front. Physiol. 2015, 6, 12. [CrossRef]

19. Bodine, S.C.; Latres, E.; Baumhueter, S.; Lai, V.K.; Nunez, L.; Clarke, B.A.; Poueymirou, W.T.; Panaro, F.J.; $\mathrm{Na}$, E.; Dharmarajan, K.; et al. Identification of ubiquitin ligases required for skeletal muscle atrophy. Science 2001, 294, 1704-1708. [CrossRef]

20. Sacheck, J.M.; Hyatt, J.P.; Raffaello, A.; Jagoe, R.T.; Roy, R.R.; Edgerton, V.R.; Lecker, S.H.; Goldberg, A.L. Rapid disuse and denervation atrophy involve transcriptional changes similar to those of muscle wasting during systemic diseases. FASEB J. 2007, 21, 140-155. [CrossRef]

21. Gennari, C.; Imbimbo, B.; Montagnani, M.; Bernini, M.; Nardi, P.; Avioli, L.V. Effects of Prednisone and Deflazacort on Mineral Metabolism and Parathyroid-Hormone Activity in Humans. Calcified Tissue Int. 1984, 36, 245-252. [CrossRef]

22. Gennari, C.; Imbimbo, B. Effects of prednisone and deflazacort on vertebral bone mass. Calcified Tissue Int. 1985, 37, 592-593. [CrossRef]

23. Pagano, G.; Bruno, A.; Cavallo-Perin, P.; Cesco, L.; Imbimbo, B. Glucose intolerance after short-term administration of corticosteroids in healthy subjects. Prednisone, deflazacort, and betamethasone. Arch. Intern. Med. 1989, 149, 1098-1101. [CrossRef]

24. Reitter, B. Deflazacort vs. prednisone in Duchenne muscular dystrophy: Trends of an ongoing study. Brain Dev. 1995, 17, 39-43. [CrossRef]

25. Angelini, C. The role of corticosteroids in muscular dystrophy: A critical appraisal. Muscle Nerve 2007, 36, 424-435. [CrossRef] 
26. Angelini, C.; Pegoraro, E.; Turella, E.; Intino, M.T.; Pini, A.; Costa, C. Deflazacort in Duchenne dystrophy: Study of long-term effect. Muscle Nerve 1994, 17, 386-391. [CrossRef]

27. Dekhuijzen, P.N.; Gayan-Ramirez, G.; Bisschop, A.; de Bock, V.; Dom, R.; Bouillon, R.; Decramer, M. Rat diaphragm contractility and histopathology are affected differently by low dose treatment with methylprednisolone and deflazacort. Eur. Respir. J. 1995, 8, 824-830.

28. Anderson, J.E.; McIntosh, L.M.; Poettcker, R. Deflazacort but not prednisone improves both muscle repair and fiber growth in diaphragm and limb muscle in vivo in the mdx dystrophic mouse. Muscle Nerve 1996, 19, 1576-1585. [CrossRef]

29. Kelly, F.J.; McGrath, J.A.; Goldspink, D.F.; Cullen, M.J. A morphological/biochemical study on the actions of corticosteroids on rat skeletal muscle. Muscle Nerve 1986, 9, 1-10. [CrossRef]

30. Kelly, F.J.; Goldspink, D.F. The differing responses of four muscle types to dexamethasone treatment in the rat. Biochem. J. 1982, 208, 147-151. [CrossRef]

31. Meikle, A.W.; Tyler, F.H. Potency and duration of action of glucocorticoids. Effects of hydrocortisone, prednisone and dexamethasone on human pituitary-adrenal function. Am. J. Med. 1977, 63, $200-207$. [CrossRef]

32. Nayak, S.; Acharjya, B. Deflazacort versus other glucocorticoids: A comparison. Indian J. Dermatol. 2008, 53, 167-170. [CrossRef]

33. Ogilvie, R.W.; Feeback, D.L. A metachromatic dye-ATPase method for the simultaneous identification of skeletal muscle fiber types I, IIA, IIB and IIC. Stain Technol. 1990, 65, 231-241. [CrossRef]

34. Waters, S.B.; Pessin, J.E. Insulin receptor substrate 1 and 2 (IRS1 and IRS2): What a tangled web we weave. Trends Cell Biol. 1996, 6, 1-4. [CrossRef]

35. Higginson, J.; Wackerhage, H.; Woods, N.; Schjerling, P.; Ratkevicius, A.; Grunnet, N.; Quistorff, B. Blockades of mitogen-activated protein kinase and calcineurin both change fibre-type markers in skeletal muscle culture. Pflugers Arch. 2002, 445, 437-443. [CrossRef]

36. Nava, S.; Gayan-Ramirez, G.; Rollier, H.; Bisschop, A.; Dom, R.; de Bock, V.; Decramer, M. Effects of acute steroid administration on ventilatory and peripheral muscles in rats. Am. J. Resp. Crit.Care Med. 1996, 153, 1888-1896. [CrossRef]

37. Yoshimura, M.; Nakamura, A.; Kobayashi, M.; Takeda, S. Deflazacort induced severe skeletal muscle wasting and inguinal herniation in normal Beagle dogs. Neuromuscular Disord. 2007, 17, 775. [CrossRef]

38. Maes, K.; Testelmans, D.; Cadot, P.; Deruisseau, K.; Powers, S.K.; Decramer, M.; Gayan-Ramirez, G. Effects of acute administration of corticosteroids during mechanical ventilation on rat diaphragm. Am. J. Resp. Crit. Care Med. 2008, 178, 1219-1226. [CrossRef]

39. Maes, K.; Agten, A.; Smuder, A.; Powers, S.K.; Decramer, M.; Gayan-Ramirez, G. Corticosteroid effects on ventilator-induced diaphragm dysfunction in anesthetized rats depend on the dose administered. Respir. Res. 2010, 11, 178. [CrossRef]

40. Pey, P.; Daminet, S.; Smets, P.M.; Duchateau, L.; Travetti, O.; Saunders, J.H. Effect of glucocorticoid administration on adrenal gland size and sonographic appearance in beagle dogs. Vet. Radiol. Ultrasound 2012, 53, 204-209. [CrossRef]

41. Karatsoreos, I.N.; Bhagat, S.M.; Bowles, N.P.; Weil, Z.M.; Pfaff, D.W.; McEwen, B.S. Endocrine and physiological changes in response to chronic corticosterone: A potential model of the metabolic syndrome in mouse. Endocrinology 2010, 151, 2117-2127. [CrossRef]

42. Jefferson, L.S.; Fabian, J.R.; Kimball, S.R. Glycogen synthase kinase-3 is the predominant insulin-regulated eukaryotic initiation factor 2B kinase in skeletal muscle. Int. J. Biochem. Cell Biol. 1999, 31, 191-200. [CrossRef]

43. Bodine, S.C.; Stitt, T.N.; Gonzalez, M.; Kline, W.O.; Stover, G.L.; Bauerlein, R.; Zlotchenko, E.; Scrimgeour, A.; Lawrence, J.C.; Glass, D.J.; et al. Akt/mTOR pathway is a crucial regulator of skeletal muscle hypertrophy and can prevent muscle atrophy in vivo. Nat. Cell Biol. 2001, 3, 1014-1019. [CrossRef]

44. Leger, B.; Cartoni, R.; Praz, M.; Lamon, S.; Deriaz, O.; Crettenand, A.; Gobelet, C.; Rohmer, P.; Konzelmann, M.; Luthi, F.; et al. Akt signalling through GSK-3beta, mTOR and Foxo1 is involved in human skeletal muscle hypertrophy and atrophy. J. Physiol 2006, 576, 923-933. [CrossRef]

45. Gundersen, K. Excitation-transcription coupling in skeletal muscle: The molecular pathways of exercise. Biol. Rev. Camb. Philos. Soc. 2011, 86, 564-600. [CrossRef]

46. Ciaraldi, T.P.; Carter, L.; Mudaliar, S.; Henry, R.R. GSK-3beta and control of glucose metabolism and insulin action in human skeletal muscle. Mol. Cell. Endocrinol. 2010, 315, 153-158. [CrossRef] 
47. Schiaffino, S.; Dyar, K.A.; Ciciliot, S.; Blaauw, B.; Sandri, M. Mechanisms regulating skeletal muscle growth and atrophy. FEBS J. 2013, 280, 4294-4314. [CrossRef]

48. Kuo, T.; Lew, M.J.; Mayba, O.; Harris, C.A.; Speed, T.P.; Wang, J.C. Genome-wide analysis of glucocorticoid receptor-binding sites in myotubes identifies gene networks modulating insulin signaling. Proc. Natl. Acad. Sci. USA 2012, 109, 11160-11165. [CrossRef]

49. Metz, H.E.; Houghton, A.M. Insulin receptor substrate regulation of phosphoinositide 3-kinase. Clin. Cancer Res. 2011, 17, 206-211. [CrossRef]

50. Katiyar, S.; Liu, E.; Knutzen, C.A.; Lang, E.S.; Lombardo, C.R.; Sankar, S.; Toth, J.I.; Petroski, M.D.; Ronai, Z.; Chiang, G.G. REDD1, an inhibitor of mTOR signalling, is regulated by the CUL4A-DDB1 ubiquitin ligase. EMBO Rep. 2009, 10, 866-872. [CrossRef]

51. Ellisen, L.W.; Ramsayer, K.D.; Johannessen, C.M.; Yang, A.; Beppu, H.; Minda, K.; Oliner, J.D.; McKeon, F.; Haber, D.A. REDD1, a developmentally regulated transcriptional target of p63 and p53, links p63 to regulation of reactive oxygen species. Mol. Cell 2002, 10, 995-1005. [CrossRef]

52. Lin, L.; Stringfield, T.M.; Shi, X.; Chen, Y. Arsenite induces a cell stress-response gene, RTP801, through reactive oxygen species and transcription factors Elk-1 and CCAAT/enhancer-binding protein. Biochem. J. 2005, 392, 93-102. [CrossRef]

53. McClung, J.M.; Judge, A.R.; Powers, S.K.; Yan, Z. p38 MAPK links oxidative stress to autophagy-related gene expression in cachectic muscle wasting. Am. J. Physiol. Cell Physiol. 2010, 298, C542-C549. [CrossRef]

54. Nishida, H.; Ikegami, A.; Kaneko, C.; Kakuma, H.; Nishi, H.; Tanaka, N.; Aoyama, M.; Usami, M.; Okimura, Y. Dexamethasone and BCAA Failed to Modulate Muscle Mass and mTOR Signaling in GH-Deficient Rats. PLoS ONE 2015, 10, e0128805. [CrossRef]

55. Britto, F.A.; Begue, G.; Rossano, B.; Docquier, A.; Vernus, B.; Sar, C.; Ferry, A.; Bonnieu, A.; Ollendorff, V.; Favier, F.B. REDD1 deletion prevents dexamethasone-induced skeletal muscle atrophy. Am. J. Physiol. Endocrinol. Metab. 2014, 307, E983-E993. [CrossRef]

56. Wang, H.; Kubica, N.; Ellisen, L.W.; Jefferson, L.S.; Kimball, S.R. Dexamethasone represses signaling through the mammalian target of rapamycin in muscle cells by enhancing expression of REDD1. J. Biol. Chem. 2006, 281, 39128-39134. [CrossRef]

57. Tsuchida, W.; Iwata, M.; Akimoto, T.; Matsuo, S.; Asai, Y.; Suzuki, S. Heat Stress Modulates Both Anabolic and Catabolic Signaling Pathways Preventing Dexamethasone-Induced Muscle Atrophy In Vitro. J. Cell. Physiol. 2017, 232, 650-664. [CrossRef]

58. Kelleher, A.R.; Pereira, S.L.; Jefferson, L.S.; Kimball, S.R. REDD2 expression in rat skeletal muscle correlates with nutrient-induced activation of mTORC1: Responses to aging, immobilization, and remobilization. Am. J. Physiol. Endocrinol. Metab. 2015, 308, E122-E129. [CrossRef]

59. Frost, R.A.; Huber, D.; Pruznak, A.; Lang, C.H. Regulation of REDD1 by insulin-like growth factor-I in skeletal muscle and myotubes. J. Cell. Biochem. 2009, 108, 1192-1202. [CrossRef]

60. Hasselgren, P.O.; Alamdari, N.; Aversa, Z.; Gonnella, P.; Smith, I.J.; Tizio, S. Corticosteroids and muscle wasting: Role of transcription factors, nuclear cofactors, and hyperacetylation. Curr. Opin. Clin. Nutr. Metab. Care 2010, 13, 423-428. [CrossRef]

61. Passaquin, A.C.; Lhote, P.; Ruegg, U.T. Calcium influx inhibition by steroids and analogs in C2C12 skeletal muscle cells. Br. J. Pharmacol. 1998, 124, 1751-1759. [CrossRef]

62. Agell, N.; Bachs, O.; Rocamora, N.; Villalonga, P. Modulation of the Ras/Raf/MEK/ERK pathway by Ca(2+), and calmodulin. Cell. Signal. 2002, 14, 649-654. [CrossRef]

63. Shi, H.; Scheffler, J.M.; Pleitner, J.M.; Zeng, C.; Park, S.; Hannon, K.M.; Grant, A.L.; Gerrard, D.E. Modulation of skeletal muscle fiber type by mitogen-activated protein kinase signaling. FASEB J. 2008, 22, 2990-3000. [CrossRef]

64. Seaberg, B.; Henslee, G.; Wang, S.; Paez-Colasante, X.; Landreth, G.E.; Rimer, M. Muscle-derived extracellular signal-regulated kinases 1 and 2 are required for the maintenance of adult myofibers and their neuromuscular junctions. Mol. Cell. Biol. 2015, 35, 1238-1253. [CrossRef]

65. DuBois, D.C.; Almon, R.R. Glucocorticoid sites in skeletal muscle: Adrenalectomy, maturation, fiber type, and sex. Am. J. Physiol. 1984, 247, E118-E125. [CrossRef]

66. Schakman, O.; Gilson, H.; Kalista, S.; Thissen, J.P. Mechanisms of muscle atrophy induced by glucocorticoids. Horm. Res. Paediat. 2009, 72, 36-41. [CrossRef] 
67. Schakman, O.; Gilson, H.; Thissen, J.P. Mechanisms of glucocorticoid-induced myopathy. J. Endocrinol. 2008, 197, 1-10. [CrossRef]

68. Macedo, A.G.; Krug, A.L.; Souza, L.M.; Martuscelli, A.M.; Constantino, P.B.; Zago, A.S.; Rush, J.W.; Santos, C.F.; Amaral, S.L. Time-course changes of catabolic proteins following muscle atrophy induced by dexamethasone. Steroids 2016, 107, 30-36. [CrossRef]

69. Ma, K.; Mallidis, C.; Bhasin, S.; Mahabadi, V.; Artaza, J.; Gonzalez-Cadavid, N.; Arias, J.; Salehian, B. Glucocorticoid-induced skeletal muscle atrophy is associated with upregulation of myostatin gene expression. Am. J. Physiol. Endocrinol. Metab. 2003, 285, E363-E371. [CrossRef]

70. Wang, R.; Jiao, H.; Zhao, J.; Wang, X.; Lin, H. Glucocorticoids Enhance Muscle Proteolysis through a Myostatin-Dependent Pathway at the Early Stage. PLoS ONE 2016, 11, e0156225. [CrossRef]

71. Gonzalez-Perez, O.; Luquin, S.; Garcia-Estrada, J.; Ramos-Remus, C. Deflazacort: A glucocorticoid with few metabolic adverse effects but important immunosuppressive activity. Adv. Ther. 2007, 24, 1052-1060. [CrossRef]

72. Kasperk, C.; Schneider, U.; Sommer, U.; Niethard, F.; Ziegler, R. Differential effects of glucocorticoids on human osteoblastic cell metabolism in vitro. Calcified Tissue Int. 1995, 57, 120-126. [CrossRef]

73. Ferraris, J.R.; Pasqualini, T.; Legal, S.; Sorroche, P.; Galich, A.M.; Pennisi, P.; Domene, H.; Jasper, H. Effect of deflazacort versus methylprednisone on growth, body composition, lipid profile, and bone mass after renal transplantation. The Deflazacort Study Group. Pediatr. Nephrol. 2000, 14, 682-688. [CrossRef]

74. Bello, L.; Gordish-Dressman, H.; Morgenroth, L.P.; Henricson, E.K.; Duong, T.; Hoffman, E.P.; Cnaan, A.; McDonald, C.M.; Investigators, C. Prednisone/prednisolone and deflazacort regimens in the CINRG Duchenne Natural History Study. Neurology 2015, 85, 1048-1055. [CrossRef]

75. Shieh, P.B.; McIntosh, J.; Jin, F.; Souza, M.; Elfring, G.; Narayanan, S.; Trifillis, P.; Peltz, S.W.; McDonald, C.M.; Darras, B.T.; et al. Deflazacort versus prednisone/prednisolone for maintaining motor function and delaying loss of ambulation: A post HOC analysis from the ACT DMD trial. Muscle Nerve 2018, 58, 639-645. [CrossRef]

(C) 2019 by the authors. Licensee MDPI, Basel, Switzerland. This article is an open access article distributed under the terms and conditions of the Creative Commons Attribution (CC BY) license (http://creativecommons.org/licenses/by/4.0/). 